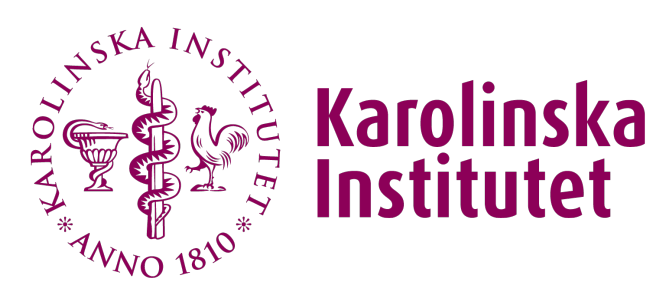

Karolinska Institutet

http://openarchive.ki.se

This is a Peer Reviewed Accepted version of the following article, accepted for publication in Toxicology.

\title{
Interactions between polycyclic aromatic hydrocarbons in complex mixtures and implications for cancer risk assessment
}

Jarvis, lan W H; Dreij, Kristian; Mattsson, Åse; Jernström, Bengt; Stenius, Ulla

Toxicology. 2014 Jul 3;321:27-39.

http://doi.org/10.1016/j.tox.2014.03.012

http://hdl.handle.net/10616/45987

If not otherwise stated by the Publisher's Terms and conditions, the manuscript is deposited under the terms of the Creative Commons Attribution-NonCommercial-NoDerivatives License (http://creativecommons.org/licenses/by-nc-nd/4.0/), which permits non-commercial re-use, distribution, and reproduction in any medium, provided the original work is properly cited, and is not altered, transformed, or built upon in any way. 


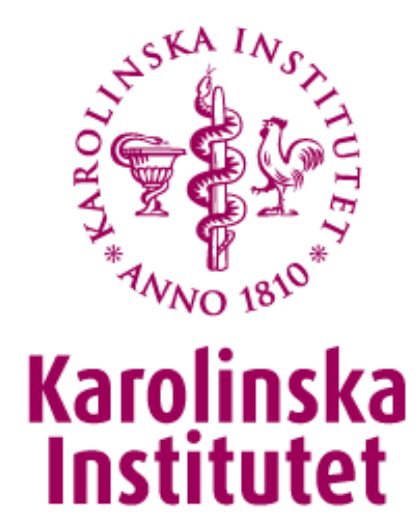

This is the peer reviewed version of the following article Toxicology. 2014 Jul 3;321:27-39. which has been published in final form at:

http://dx.doi.org/10.1016/j.tox.2014.03.012

Interactions between polycyclic aromatic hydrocarbons in complex mixtures and implications for cancer risk assessment.

Jarvis, Ian WH; Dreij, Kristian; Mattsson, A; Jernström, B; Stenius, Ulla

Access to the published version may require subscription. Published with permission from: Elsevier 
Interactions between polycyclic aromatic hydrocarbons in complex mixtures and implications for cancer risk assessment

Ian WH Jarvis*, Kristian Dreij, Åse Mattsson, Bengt Jernström, Ulla Stenius

Institute of Environmental Medicine, Karolinska Institutet, Box 210, SE-171 77 Stockholm, Sweden

* Corresponding Author

Dr. Ian Jarvis

Address: Institute of Environmental Medicine, Karolinska Institutet, Box 210, SE-171 77

Stockholm, Sweden

Email: ian.jarvis@ki.se

Tel: +46852487769

Fax: +46 8343849 


\begin{abstract}
Abbreviations
AhR, Aryl hydrocarbon receptor; ATM, ataxia telangiectasia mutated; ATR, ataxia telangiectasia and Rad3-related protein; $\mathrm{B}[a] \mathrm{P}$, benzo $[a]$ pyrene; $\mathrm{B}[a] \mathrm{P}_{\text {eq }}, \mathrm{B}[a] \mathrm{P}$-equivalent; Chk1, checkpoint kinase 1; CT, coal tar; CYP, cytochrome P450; DE, diol epoxide; DNA-PK, DNA-dependent protein kinase; DPE, diesel particulate extract; DPM, diesel particulate matter; EFSA, European Food Safety Agency; H2AX, H2A histone family member X; HEL, human embryonic lung; IARC, International Agency for Research on Cancer; MAF, mixture assessment factor; NTP, National Toxicology Program; PAH, polycyclic aromatic hydrocarbon; PCB, polychlorinated biphenyl; PCDD, polychlorinated dibenzo-p-dioxin; PCDF, polychlorinated dibenzofuran; PCN, polychlorinated naphthalene; PEF, potency equivalency factor; ROS, reactive oxygen species; RPF, relative potency factor; SRM, standard reference material; TBA, tumor bearing animal; TEF, toxic equivalency factor; UD, urban dust;
\end{abstract}




\begin{abstract}
In this review we discuss the effects of exposure to complex PAH mixtures in vitro and in vivo on mechanisms related to carcinogenesis. Of particular concern regarding exposure to complex PAH mixtures is how interactions between different constituents can affect the carcinogenic response and how these might be included in risk assessment. Overall the findings suggest that the responses resulting from exposure to complex PAH mixtures is varied and complicated. More- and less-than additive effects on bioactivation and DNA damage formation have been observed depending on the mixtures studied, and equally dependent on the different test systems that are used. Furthermore, the findings show that the commonly used biological end-point of DNA damage formation is insufficient for studying mixture effects. At present the assessment of the risk of exposure to complex PAH mixtures involves comparison to individual compounds using either a surrogate or a component-based potency approach. We discuss how future risk assessment strategies for complex PAH mixtures should be based around whole mixture assessment in order to account for interaction effects. Inherent to this is the need to incorporate different experimental approaches using robust and sensitive biological endpoints. Furthermore, the emphasis on future research should be placed on studying real life mixtures that better represent the complex PAH mixtures that humans are exposed to.
\end{abstract}

\title{
Key Words
}

Benzo[ $[a]$ pyrene; Cancer; Complex Mixtures; Polycyclic Aromatic Hydrocarbons; Risk Assessment 


\section{Introduction}

The field of mixture toxicology and the experimental analysis of chemical mixtures have undergone a significant expansion borne out of the need to understand the effects of exposure on human health. Historically, experimental approaches have focused on understanding the effects of individual or simple combinations of chemicals. However, this approach is being superseded in favor of investigating the effects of complex mixtures and understanding of the interactions between different chemicals. A review published in the early 1990's summarized the then status of toxicological assessment of complex mixture effects (Mauderly 1993). That the issues pertaining to complex mixture assessment presented at that time are still as prevalent today highlights the challenges faced by researchers in this field.

Humans are exposed to complex mixtures of chemicals through various sources including occupational settings, the environment, cigarette smoking, vehicular exhaust emissions, pharmaceuticals, lifestyle products and foodstuffs. Exposure occurs over a prolonged period of time and generally at low levels. Typically this exposure includes a vast assortment of chemicals including, but not limited to, polycyclic aromatic hydrocarbons (PAHs), polychlorinated biphenyls (PCBs), dibenzo-p-dioxins (PCDDs), dibenzofurans (PCDFs) and naphthalenes (PCNs), pesticides and heavy metals. There is however a significant lack of information available today regarding complex mixture toxicology.

A major group of chemicals that are found in complex mixtures are the PAHs, a family of more than 1500 compounds (NTP 2012) comprised of two or more fused aromatic rings, found both in their native and substituted forms (i.e. methylated, oxygenated or nitrated) (Figure 1). PAHs are ubiquitous environmental pollutants that are formed as a result of incomplete pyrolytic processes and to which humans are exposed through inhalation, ingestion and dermal absorption. Links 
between human exposure to complex PAH mixtures and development of diseases including cancer, and respiratory and cardiovascular diseases have been described previously (ATSDR 1995; Boffetta et al. 1997; IARC 2010; Peters et al. 2001; Pope et al. 2002). Despite their structural similarities, PAHs vary greatly in their carcinogenic potency, with both individual and complex mixtures of PAHs classified as possible or probable human carcinogens by the International Agency for Cancer Research (IARC) (IARC 2010).

Assessment of the carcinogenic risk to humans of exposure to PAHs often involves comparison to benzo $[a]$ pyrene $(\mathrm{B}[a] \mathrm{P})$ and two approaches are commonly used (Boström et al. 2002; Pufulete et al. 2004). In the first approach $\mathrm{B}[a] \mathrm{P}$ is used as a surrogate marker to determine quantitative risk estimates for mixtures of PAHs in air (WHO 2000) or food (EFSA 2008). The second approach is component-based in which the potency of different PAHs is expressed relative to that of $\mathrm{B}[a] \mathrm{P}$ (assigned a nominal value of 1). The assigned values for the different PAHs are termed Relative Potency Factors (RPF) or Toxic Equivalency Factors (TEF)/Potency Equivalent Factors (PEF). Detailed description of the differences between how the factors are derived have been published previously (Backhaus et al. 2010; U.S.EPA 2000). An important issue regarding the componentbased approach is that due to a lack of data not all PAHs have been assigned potency values and this is likely to lead to a misestimating of the risk. Principles pertaining to how risk assessments could be applied to complex PAH mixtures have been proposed (ATSDR 2004; EC 2009; Flowers et al. 2002; IPCS 2009; NTP 2012; SCHER et al. 2012; U.S.EPA 2007; U.S.EPA 2010), and indeed a recent research proposal testing the health effects of complex PAH mixtures has been approved (NTP 2012). However, it is accepted that due a number of limiting factors (discussed in detail below) this is likely to lead to misestimating of the risk to human health.

The aim of this paper is to review what is currently known about the effects of interactions between PAHs in complex mixtures on mechanisms related to carcinogenesis. We then discuss ways and 
advantages of studying complex PAH mixtures and how such findings could be applied to future risk assessment.

\section{Carcinogenic effects of PAHs}

The binding of PAHs to DNA and the associated effects that occur as a result is considered the major mechanism of PAH-induced mutagenesis and carcinogenesis. Like many chemical carcinogens, PAHs require activation through a series of enzymatically-catalyzed reactions to form their active metabolites (Conney 1982; Huberman et al. 1976; Sims et al. 1974). The CYP family of enzymes, in particular CYP1A1, 1A2 and 1B1, are primarily involved in bioactivation of PAHs to their reactive intermediates (Pelkonen and Nebert 1982; Shimada and Fujii-Kuriyama 2004; Shimada et al. 1996). Many PAHs are ligands for the aryl hydrocarbon receptor (AhR), which has different roles involved in metabolism including regulation of the different bioactivating and detoxifying enzymes (Baird et al. 2005; Nebert et al. 2004). For example, B $[a] \mathrm{P}$ is activated through a three-step enzymatic mechanism involving initial metabolism by CYP enzymes to $\mathrm{B}[a] \mathrm{P}$ 7,8-epoxides, followed by conversion to $\mathrm{B}[a] \mathrm{P}-7,8$-diols by epoxide hydrolase, and final transformation to the ultimate reactive $\mathrm{B}[a] \mathrm{P}-7,8$-diol-9,10-epoxide metabolites, again by CYP enzymes (Conney 1982). This mechanism of activation has also been shown for other PAHs. An additional metabolic pathway is the aldo-keto reductase mechanism that activates PAHs to redoxactive o-quinone derivatives which might also have tumorigenic and mutagenic activities (Park et al. 2008; Penning et al. 1999; Zhang et al. 2012). Although many substituted PAHs are also targets for CYPs, their bioactivation often involves additional steps. For example, nitrated PAHs (such as 1-nitropyrene) require initial nitroreduction to primary amines before they are metabolized by CYPs to hydroxylamines and activated by conjugation reactions (Chou and Fu 1983; Djuric et al. 1986). 
The tumorigenic and mutagenic activities of many PAHs have been linked to the ability of their diol epoxide (DE) metabolites to bind covalently to exocyclic amino groups on purine bases to form either stable bulky PAH-DE-DNA adducts or depurinating adducts which are released from DNA leaving abasic sites (Rogan et al. 1993; Sims and Grover 1974; Szeliga and Dipple 1998). Quinones can also bind DNA and form stable N2-dG or N2-dA adducts (Penning et al. 1999; Shou et al. 1993) or depurinating N7-dG adducts (McCoull et al. 1999). PAHs exhibit a large variety in their ability to form adducts with DNA which may be a result of different structural conformations. Most carcinogenic PAHs contain either a bay or a fjord region within their structure (Figure 1). PAHs containing a bay region (i.e. $\mathrm{B}[a] \mathrm{P}$ ) are rigid and planar and their DEs typically react with guanine residues, whereas those containing a fjord region (i.e. dibenzo[a,l]pyrene, also known as dibenzo[def,p]chrysene) are sterically hindered and non-planar and typically react with adenine residues. Studies comparing the biological activity of bay- and fjord-region containing PAHs have shown that the latter in general have a higher mutagenic and tumorigenic potential (Dipple et al. 1987; Jerina et al. 1986; Ralston et al. 1995; Szeliga and Dipple 1998). The variation in potencies is most probably associated with the structural differences between adducts and the subsequent effects on removal by DNA repair mechanisms (Buterin et al. 2000; Dreij et al. 2005; Kropachev et al. 2013; Suh et al. 1995). However, it could also be a result of changes in DNA polymerase activity and incorrect base-pair insertion resulting from post-lesion DNA synthesis (Broyde et al. 2010; Eoff et al. 2010; Huang et al. 2003).

Following bioactivation and reaction with DNA, the PAH metabolites can induce mutations that either activate oncogenes or inactivate tumor suppressor genes as part of their carcinogenic mechanism. This process can be exacerbated in complex PAH mixtures as they might contain compounds that alone have weak carcinogenic potential (e.g. promoters) but in combination with initiators act in an additive or more-than additive manner (Baird et al. 2005; U.S.EPA 2007). If mutations occur in tumour suppressors this can lead to uncontrolled cell cycle regulation, 
accumulation of DNA damage and ultimately carcinogenesis. For example, the p53 tumor suppressor gene is mutated in many human cancers (Hainaut et al. 1998; Hollstein et al. 1991) and exposure to PAHs has previously been associated with mutations in p53 in human lung and breast cancers (Hussain et al. 2001; Mordukhovich et al. 2010). The Ras proto-oncogene is mutated in a large number of human cancers (Bos 1989; Prior et al. 2012) and associations with PAH exposure have been observed in vivo (Gray et al. 2001; Ross and Nesnow 1999).

In addition to the above described mechanisms, generation of reactive oxygen species (ROS) and oxidative DNA damage can occur. Induction of oxidative stress is a major mode of toxicity associated with airborne particles to which PAHs can be absorbed. This includes responses such as formation of oxidative DNA damage, triggering of an inflammatory response and cell death (Lodovici and Bigagli 2011). Oxidative DNA damage can result from PAHs undergoing rounds of futile redox cycling leading to the formation of 8-oxo-dGuo adducts with subsequent induction of mutations (Park et al. 2005; Park et al. 2006). However, it is often very hard to ascertain the contribution of oxidative DNA damages on PAH-induced carcinogenesis, in part because such damages are formed in parallel with DNA adducts, and thus, to date, the role of oxidative stress in PAH mixture toxicology remains unclear.

Pro-carcinogenic epigenetic mechanisms are evidenced as heritable changes that do not involve direct modification of the DNA sequence (Esteller 2008; Jones and Baylin 2007). Epigenetic changes including DNA methylation and telomere dysfunction have been reported after exposure to complex PAH mixtures in human workers and following in vivo mouse exposure (Bollati et al. 2007; Pavanello et al. 2009; Pavanello et al. 2010; Yauk et al. 2008), and the effects of epigenetic changes on PAH-induced carcinogenesis warrants further investigation.

\section{Bioactivation of PAH mixtures and reaction with DNA}


In this section of the review the effects of interactions between PAHs in mixtures and the effects on bioactivation (i.e. effects on either expression or activity of metabolic enzymes like CYPs) and reaction with DNA (i.e. formation of adducts) is discussed. For this purpose we have sub-divided this section into two parts - interactions in binary PAH mixtures and those in complex PAH mixtures. To allow for comparisons of interaction effects we have mainly focused on studies that have co-exposed and compared effects of individual PAHs (such as $\mathrm{B}[a] \mathrm{P}$ ) with mixtures.

One aspect of the mechanism behind PAH-induced carcinogenesis that will not be discussed in this review is analysis of mutagenicity after exposure to complex PAH mixtures. Whilst this is a significant area of research for mixture effects, many of the studies have already been extensively reviewed in great detail previously (Claxton et al. 2004; Ohe et al. 2004; White 2002; White and Claxton 2004).

\subsection{Effects of interactions in binary PAH mixtures}

Early in vivo studies involved topical exposure of mice to binary PAH mixtures to investigate interaction effects on DNA binding (usually formation of $\mathrm{B}[a] \mathrm{P}-\mathrm{DE}-\mathrm{DNA}$ adducts) and these are summarized in Table 1 . Increased binding of $\mathrm{B}[a] \mathrm{P}$ to $\mathrm{DNA}$ in vivo was the more prevalent observation following co-exposure of $\mathrm{B}[a] \mathrm{P}$ with a number of $\mathrm{PAHs}$ including benzo[e $]$ pyrene, dibenzo[a,e]pyrene, dibenzo[a,l]pyrene, fluoranthene or pyrene (Hughes and Phillips 1990; Rice et al. 1988; Rice et al. 1984; Slaga et al. 1979; Smolarek et al. 1987). Conversely, in vivo co-exposure of $\mathrm{B}[a] \mathrm{P}$ with phenanthrene decreased DNA adduct formation (Rice et al. 1984), and with a mixture comprised of $\mathrm{B}[a] \mathrm{P}$ with dibenzo[a,e]pyrene and dibenzo $[a, l]$ pyrene, levels of DNA adducts were lower than observed for the individual PAHs (Hughes and Phillips 1990). Furthermore, topical co- 
exposure of 7,12-dimethylbenz[a]anthracene with benzo[e]pyrene decreased binding of the former to mouse DNA (DiGiovanni et al. 1982; Slaga et al. 1979; Smolarek et al. 1987).

Whilst the above described studies did not investigate effects on bioactivation, the authors concluded that in the presence of different PAHs, activation leading to DNA binding intermediates is likely to be altered. In addition, it is also possible that the observed adduct levels in some studies could result from interactions affecting the activation of DNA repair systems. More recent in vitro and in vivo studies have investigated effects of binary PAH mixtures (Table 1). In in vitro studies using human-derived hepatocellular carcinoma (HepG2) cells exposed to binary PAH mixtures, increased levels of DNA adducts and expression of CYPs were generally observed compared to B[a]P alone (Cherng et al. 2001; Gabelova et al. 2013; Sevastyanova et al. 2007; Staal et al. 2007; Tarantini et al. 2011). Whilst the authors of these manuscripts attributed these responses to additive or more-than additive effects, only two of the manuscripts based these observations on different mathematical models of additivity (Gabelova et al. 2013; Staal et al. 2007) whereas the remaining observations were inferred from dose addition effects. Similar effects on CYP-mediated metabolism were observed in vivo in male Sprague-Dawley rats exposed to binary PAH mixtures (Bouchard et al. 1998) and increased DNA adduct levels have been observed in vitro in hamster embryo cells exposed to a mixture of $\mathrm{B}[a] \mathrm{P}$ and benzo[e]pyrene (Smolarek and Baird 1984). A recent in vitro study in human-derived colorectal adenocarcinoma (HT-29) cells observed dose-dependent increased fluoranthene metabolism after co-exposure with $\mathrm{B}[a] \mathrm{P}$ which the authors attributed to enhanced CYP-mediated activation of fluoranthene, although neither gene expression or CYP activity was measured directly (Harris et al. 2013).

Lower levels of DNA adducts and CYP expression after exposure to binary PAH mixtures have been observed in vitro in HepG2 and human embryonic lung (HEL) cells (Binkova and Sram 2004; Cherng et al. 2006; Sevastyanova et al. 2007), and whilst the responses in these studies are 
consistent with less-than additive effects resulting from interactions, no appropriate mathematical calculation of additivity was included on which to confirm this. For the former it is likely that these contrasting findings in the HepG2 cells result from the use of high $\mathrm{PAH}$ concentrations $(\mathrm{B}[a] \mathrm{P} 10$ $\mu \mathrm{M}$ ) and related effects on CYP inhibition as a result of elevated ROS formation (Cherng et al. 2006). For the latter this response probably results from the low metabolic capacity of HEL cells and the resulting decrease in PAH activation (Binkova and Sram 2004; Sevastyanova et al. 2007). Lower levels of DNA adducts and CYP expression/activity have in general been observed in vitro in rat cells (Falahatpisheh et al. 2004; Gabelova et al. 2013; Staal et al. 2008) and in vivo in killifish (Willett et al. 2001) and zebrafish (Van Tiem and Di Giulio 2011), and whilst the authors suggested these represented less than additive effects due to interactions, these conclusions were based on dose addition observations whereas only two studies applied mathematical modelling (Gabelova et al. 2013; Staal et al. 2008). It is possible that these contrasting findings result from differences between human- and experimental animal-derived cells and this conclusion is in agreement with the observed variations in sensitivity to TCDD (Silkworth et al. 2005). However, as the respective studies did not use the same test conditions (mixtures, exposure times, concentrations etc.) this conclusion regarding species sensitivity cannot fully account for the differences in response and it is probable that there are many different sources that contribute to the outcome.

An important caveat to consider for many of the above described studies on binary mixture effects in vitro is the used of the human HepG2 cell line. This particular cell line is one of the most extensively used for studying the effects of PAHs due to its demonstrated metabolic competency. However the result of this widespread use is that the particular cell line likely exists in many different clonal variants that might lack the inducibility of particular enzymes involved in bioactivation of PAHs. For example, it has been shown that hypermethylation of the CYP1B1 gene promoter leads to a lack of induction of CYP1B1 after exposure to dioxin (Beedanagari et al. 2010) and this is another consideration that might explain the differences observed in the above described 
studies. Furthermore this is a consideration that applies to all experimental cell lines and is an important reason for maintaining and using cells at low passage numbers to prevent accumulation of clonal differences.

In conclusion, the studies on binary PAH mixtures suggest that saturation of activation is an important consideration when studying interaction effects, and that the use of experimental models plays as important a role as the different mixtures studied. However, as there is a lack of consistency between the experimental conditions in the above described studies it is impossible to determine the driving source behind the observed differences. Since the described studies do not show a consistent effect in response to binary PAH mixtures on DNA damage levels, this suggests that formation of DNA damage is an inadequate marker for mixture effects.

\subsection{Effects of interactions in complex PAH mixtures}

To discuss interaction effects we have focused on studies where exposure to complex PAH mixtures has been investigated alongside exposure to individual PAHs. Studies that have investigated complex PAH mixtures have typically used two different types: either standard reference materials (SRM) or extracts obtained from collected environmental samples. SRMs from the National Institute of Standards and Technology have been used: from coal tar (CT, SRM1597, SRM1597a), from urban dust (UD, SRM 1649a), from diesel particulate extract (DPE, SRM1650b) and from diesel particulate matter (DPM, SRM1975) (May et al. 1992).

Two recently published reviews have extensively discussed transcriptional responses after exposure to complex PAH mixtures in vitro and in vivo from original studies and as such these effects have not been included (Huang 2013; Sen et al. 2007). Both reviews conclude that in vitro microarray 
analysis patterns provide a comprehensive approach to assessing effects on gene expression that complement animal experiments.

The effects of exposure to SRMs both in vitro and in vivo are summarized in Table 2. Levels of DNA adducts in female SENCAR mice exposed in vivo to $\mathrm{CT}$ or UD with either $\mathrm{B}[a] \mathrm{P}$ or dibenzo[ $[a, l]$ pyrene decreased compared to the individual PAHs alone, although there was no clear correlation between adduct levels and change in CYP expression (Courter et al. 2007a; Marston et al. 2001). Similarly, lower levels of DNA adducts were observed in vitro in human-derived breast adenocarcinoma (MCF-7) cells and Chinese-hamster-derived lung fibroblast (V79) cells exposed to CT, UD or DPE with either B[a]P or dibenzo[a,l]pyrene (Mahadevan et al. 2005a; Mahadevan et al. 2005b; Mahadevan et al. 2007; Musafia-Jeknic et al. 2005). The decreases in DNA adduct levels are probably a result of increased competition for substrate binding to activating enzymes. In contrast, DNA adduct levels increased in female SENCAR mice exposed in vivo to DPE with either B $[a] \mathrm{P}$ or dibenzo[a,l]pyrene compared to the individual PAHs alone although again there was no clear correlation between adduct levels and change in CYP expression or activity (Courter et al. 2008). This difference in DNA adduct formation may be attributable to the higher amounts of DPE (50 $\mathrm{mg}$ ) these mice were exposed to compared to the amount of either CT or UD (1 mg). It is also plausible that different PAHs in the DPE could be causing additive or more-than additive effects on DNA adduct formation, although in human-derived MCF-10A cells in vitro co-exposure of DPE with $\mathrm{B}[a] \mathrm{P}$ caused decreased levels of $\mathrm{DNA}$ adducts compared to $\mathrm{B}[a] \mathrm{P}$ alone, and co-exposure with dibenzo[a,l]pyrene caused no significant change (Courter et al. 2007b). Taken together these findings suggest that the response to complex PAH mixtures is likely attributable to inhibitory effects on activation resulting from particular PAHs in the mixture and potentially also the effects of metabolic enzyme saturation leading to less than additive effects although this was not mathematically modelled. Similar to the above described binary studies, these studies also suggest that DNA damage formation might not be a good marker for mixture effects. 
To discuss the effects of interactions we have focused on studies that have co-exposed mixtures with individual PAHs and compared the effects. There is however a number of recent studies that have investigated the effects of exposure to complex PAH mixtures on DNA adduct formation compared to exposure to individual PAHs (without co-exposure). Exposure of human-derived BEAS-2B or MCF-7 cells or HEL cells in vitro to either SRMs or environmental PAH mixture extracts typically resulted in decreased levels of DNA adducts compared to $\mathrm{B}[a] \mathrm{P}$ alone, although it is not always entirely clear the motivation for the choice of mixture concentration and it is plausible these decreases are reflective of the use of different concentrations (i.e. higher $\mathrm{B}[a] \mathrm{P}$ when used alone than what is in the mixtures) (Binkova and Sram 2004; Kuljukka-Rabb et al. 2001; Oh et al. 2011; Pohjola et al. 2003; Rossner et al. 2013; Sevastyanova et al. 2007). Similarly, in vitro exposure of rat-derived WB-F344 cells or in vivo exposure of female FVB/N mice to complex PAH mixtures resulted in decreased levels of DNA adducts compared to $\mathrm{B}[a] \mathrm{P}$ alone (Andrysik et al. 2011; Siddens et al. 2012). These findings suggest that interactions in complex PAH mixtures typically lead to less-than additive effects, similar to what was observed in the in vivo co-exposure experiments (Courter et al. 2008; Courter et al. 2007a; Marston et al. 2001). However, in in vitro studies using HepG2 cells increased DNA damage (both adducts and strand breaks) was observed after exposure to complex PAH mixtures suggesting additive/more-than additive effects of interactions (Niziolek-Kierecka et al. 2012; Sevastyanova et al. 2007; Tarantini et al. 2009). However, for both scenarios the assumptions of interaction effects are based on dose addition observations and were not determined mathematically. This is in agreement with the results obtained using binary PAH mixtures in HepG2 cells and probably reflects the metabolic competency of these cells (Knasmuller et al. 1998). Whilst interaction effects are not possible to determine and the proposed conclusions regarding additivity are based on simple dose addition observations, these studies show decreased levels of adducts with mixtures than with $\mathrm{B}[a] \mathrm{P}$ which 
is in agreement with the above described co-exposure experiments indicating that analysis of $\mathrm{B}[a] \mathrm{P}$ alone is not sufficient as a surrogate for mixture effects.

In conclusion, the observed effects resulting from exposure to complex PAH mixtures are similar to what was observed with binary PAH mixtures in that the response was dependent on many different contributory factors including the test system and mixtures assessed, and was not predictable from comparison to individual PAHs. However, similar to the conclusion from the binary studies the lack of coherence between the experimental conditions makes it impossible to determine the overall driving source of the responses.

\section{Carcinogenicity of PAH mixtures}

\subsection{PAH exposure and cancer in humans}

High exposures to PAHs in occupational settings are of significant risk to humans. Accordingly, IARC lists $\mathrm{B}[a] \mathrm{P}$ and a number of industrial complex $\mathrm{PAH}$ mixtures including coal tars, mineral oils, shale oils and soot and exposure through cigarette smoke, aluminium production, coal gasification and coke production as carcinogenic to humans (IARC 2010). In addition, there are a number of individual PAHs and mixtures/exposures classified as groups 2A (probably carcinogenic) and 2B (possibly carcinogenic) (IARC 2010). Case-control studies on human workers exposed to PAHs through their occupation and also through dietary exposure have been extensively described previously (Boffetta et al. 1997; Bosetti et al. 2007; IARC 2010). From the case control studies human cancers associated with occupational exposure were observed in a large number of sites including the respiratory system, larynx, bladder, esophagus/stomach, skin and kidney. The most prevalent form of cancer from occupational exposure to complex PAH mixtures was found in the lungs (Boffetta et al. 1997; Bosetti et al. 2007; IARC 2010). 
In addition to the above described occupational risk, a large number of factors have been linked to exposure to complex PAH mixtures and cancer. These include smoking, cooking and dietary intake and wood burning. Tobacco smoking is considered the overwhelming cause of lung cancer in humans and is associated with approximately $90 \%$ of all lung cancer incidences and 1.2 million deaths per year worldwide (DeMarini 2004; IARC 2004). In addition, smoking has been identified as a cause of cancer in a number of other human organ sites (IARC 2004). $\mathrm{B}[a] \mathrm{P}$ was one of the first carcinogenic compounds detected in tobacco smoke, and the links between tobacco smoking, $\mathrm{B}[a] \mathrm{P}$ and DNA damage have been reviewed recently (Alexandrov et al. 2010). Dietary exposure to complex PAH mixtures is also a significant risk for human cancer development (Phillips 1999), and moreover, is the primary route of non-occupational exposure for non-smokers. A number of human cancers have been associated with dietary intake of complex PAH mixtures including colorectal, pancreatic and prostate (IARC 2010). In addition to food consumption, cooking has also been linked to development of human cancer. Investigations in the county of Xuan Wei, China, showed unusually high levels of lung cancer mortality rates. In this area, residents (particularly women) are exposed to high levels of unvented smoke from indoor cooking resulting in high level and chronic exposure to complex PAH mixtures which was highly associated with lung cancer development (Chuang et al. 1992; DeMarini et al. 2001). More work is required to fully understand the cellular mechanisms involved in carcinogenesis but it is evident that exposure to PAHs in all these scenarios is a major contributor to the observed cancers.

\subsection{Carcinogenic effects of PAH mixtures in experimental animals}

In the two-stage model tumors can be induced by application of an initiator (carcinogenic PAH, sub-threshold dose) followed by repetitive exposure to a promoter (Mason et al. 1990; Nesnow et al. 1983). Over 100 PAHs and their metabolites are known to be tumor initiators or complete 
carcinogens in the mouse skin two-stage model (Nesnow et al. 1983; Pereira 1982) with the consequence that interactions most likely alter the response to complex PAH mixtures compared to individual PAHs.

Studies on binary PAH mixtures have shown that weak or non-carcinogenic PAHs have various influences on the tumor-initiating activities of PAHs with stronger carcinogenic potential (Table 1). Dermal exposure of mice to $\mathrm{B}[a] \mathrm{P}$ with various $\mathrm{PAHs}$ caused an increase in tumor initiation which correlated with increased DNA binding. Conversely, dermal co-exposure of 7,12dimethylbenz $[a, h]$ anthracene with the same PAHs caused a decrease in tumor initiation which correlated with decreased 7,12-dimethylbenz $[a, h]$ anthracene binding to DNA (DiGiovanni et al. 1982; Slaga et al. 1979). It was suggested that the co-exposed PAHs might be affecting the metabolism to DNA-reactive metabolites. In a dose-response study performed in mice it was found that quintary PAH mixtures exhibited more than additive effects at low doses and less than additive effects at high doses when lung adenomas were scored compared to individual PAH exposure (Nesnow et al. 1998). This paradoxical finding (i.e. non-linear dose-effect relationship) probably results from competitive inhibition of the metabolizing enzymes and hence decreased amounts of DNA-reactive metabolites and fits with the findings of the above described studies on binary and complex PAH mixtures.

Tumor induction resulting from exposure to complex PAH mixtures has been studied in vivo using a number of different exposure routes including oral (Culp et al. 1998; Goldstein et al. 1998; Weyand et al. 1995), gavage (Robinson et al. 1987), dermal (Deutsch-Wenzel et al. 1984; Grimmer et al. 1985; Grimmer et al. 1983; Grimmer et al. 1982; Nesnow et al. 1983) and lung implantation (Grimmer et al. 1988; Grimmer et al. 1987a; Grimmer et al. 1987b; Grimmer et al. 1984). A review by Schneider et al. (2002) of some of these earlier tumor induction studies concluded that the contribution of $\mathrm{B}[a] \mathrm{P}$ to the overall potency of the PAH mixtures depends on the route of exposure 
and the end-point studied (i.e. the cancer type) (Schneider et al. 2002). More recent studies using the dermal tumour initiation mouse model and co-exposure of complex PAH mixtures with either $\mathrm{B}[a] \mathrm{P}$ or dibenzo $[a, l]$ pyrene are summarized in Table 3 with the reported effects on numbers of tumors per tumor bearing animal (TBA) as an indicator of response (Courter et al. 2008; Courter et al. 2007a; Marston et al. 2001). One important conclusion was that the formation of DNA adducts in the skin (after single administration) did not predict the final tumor response suggesting that DNA adduct formation is a poor marker for tumorigenesis induced by complex PAH mixtures.

In these studies when the complex $\mathrm{PAH}$ mixtures were co-exposed with either $\mathrm{B}[a] \mathrm{P}$ or dibenzo $[a, l]$ pyrene increased numbers of tumour/TBA were observed compared to the mixture alone, whereas no effect or decreased numbers of tumors/TBA were observed when compared to exposure to $\mathrm{B}[a] \mathrm{P}$ or dibenzo $[a, l]$ pyrene alone (Table 3 ). Taken at face value these findings seem to suggest that the effects on tumors/TBA are solely governed by the application of the individual PAHs. In the study published by Siddens et al. (2012) these discrepancies were discussed in the context of RPF values and how using values from the U.S. EPA the RPF value for a mixture of DPM and $\mathrm{CT}$ would be $0.34 \mu \mathrm{g} \mathrm{B}[a] \mathrm{P}$-equivalent $\left(\mathrm{B}[a] \mathrm{P}_{\mathrm{eq}}\right)$. In comparison to $\mathrm{B}[a] \mathrm{P}$, which was used at $100 \mu \mathrm{g}$, it would be predicted that the mixtures would elicit a much weaker tumor response. However, their results showed no differences in incidence, latency, multiplicity or tumor type between the two exposures showing that the observed tumor effects in response to the complex mixture were higher than anticipated based on current RPF values (Siddens et al. 2012). It should however be considered that not all PAHs in the mixtures tested would have been assigned RPF values due to the lack of experimental data which could lead to misestimating of the mixture potency.

Using a similar approach we calculated the corresponding $\mathrm{B}[a] \mathrm{P}_{\mathrm{eq}}$ values of the CT, DPE and UD mixtures used in three recent mice studies (Courter et al. 2008; Courter et al. 2007a; Marston et al. 
2001). The RPF values were $0.23,0.28$ and $0.015 \mu \mathrm{g} \mathrm{B}[a] \mathrm{P}_{\text {eq }}$ respectively, to be compared with the $50.4 \mu \mathrm{g} \mathrm{B}[a] \mathrm{P}$ used and in stark difference to the observed numbers of tumors/TBA which differed around a factor of 3. These results support the observation from Siddens et al. (2012) that much weaker responses than were observed would be predicted, and highlights the inadequacy of the current RPF system for complex PAH mixtures which is further discussed below.

\section{Risk assessment of complex PAH mixtures}

\subsection{Risk assessment approaches for PAHs}

Cancer risk assessment of PAHs typically encompasses three approaches $-\mathrm{B}[a] \mathrm{P}$ as a surrogate marker for mixture exposure, the use of component-based factors (such as RPF and TEF values) or the comparative potency approach (Flowers et al. 2002; IPCS 1998; Pufulete et al. 2004). The first approach has been applied to determine risk of exposure to PAHs in air (WHO 2000) and by the European Food Safety Agency (EFSA) as a marker for PAH levels in foods (EFSA 2008). EFSA further investigated the use of mixtures of other PAHs (PAH4 and PAH8) and concluded these were more appropriate markers of PAH exposure in foodstuffs (EFSA 2008). However, the necessary assumption that relative PAH concentrations will remain stable between different exposure scenarios is a major weakness for ubiquitous PAH mixtures and both agencies concluded that the surrogate marker approach is likely to misestimate the actual risk of exposure to humans. In the second approach the different components of the PAH mixtures (where identifiable) are assigned potency factors relative to $\mathrm{B}[a] \mathrm{P}$ (i.e. RPF or $\mathrm{TEF}$ values) and from these factors cancer risk estimates for PAH mixtures can be derived. Risk estimates are determined by calculating and summing $\mathrm{B}[a] \mathrm{P}_{\mathrm{eq}}$ values for the different $\mathrm{PAHs}$ in the mixtures, and as described above, this can be limited by a lack of potency values for all PAHs. To adjust for possible adverse effects resulting from interactions uncertainty factors (or safety factors) are often included in risk assessments 
(ECETOC 2003; ECETOC 2010; KEMI 2003; Martin et al. 2013). The final approach assesses the whole PAH mixture by estimating the potency without having to identify or quantify individual PAH compounds. Using a source-specific PAH mixture which has been thoroughly characterized in epidemiological and biological studies as a reference, a second sufficiently similar PAH mixture is ranked based on its comparative potency in the biological test. This approach has been suggested for a variety of complex PAH mixtures (Albert et al. 1983; Lewtas 1985), although to the authors' knowledge, has yet to be implemented by regulatory agencies. In the following section the limitations of these approaches to complex PAH mixture risk assessment are discussed and then an alternative approach based on whole mixture assessment is presented.

\subsection{Limitations of the current approaches for PAH mixture risk assessment}

Risk assessment of complex PAH mixtures is a challenging issue. As discussed throughout this review there is a growing consensus that the current approaches to risk assessment are insufficient. The weaknesses of these approaches regarding complex PAH mixture assessment are outlined below.

- Ubiquitous nature of complex PAH mixtures: The composition of complex PAH mixtures in the environment varies significantly depending on location sampled, time/season of sampling and surrounding industrial and vehicular use. This means that analysis of a surrogate $\mathrm{PAH}$ (i.e. $\mathrm{B}[a] \mathrm{P}$ ) for whole mixtures is unreliable when predicting human risk. An option to restrict this limitation has been suggested involving identification of typical PAH profiles or "fingerprints" correlated to the different sources (Howsam and Jones 1998; Ravindra et al. 2008; Tobiszewski and Namieśnik 2012).

- Lack of a common mechanism for PAHs: For the component-based approach (i.e. using RPF or TEF values) to be valid for complex PAH mixture risk assessment it requires a common mode of action and observed additivity in the resulting toxicological effect. The 
heterogeneous mechanisms that are likely to occur for different PAHs (Boström et al. 2002) predispose that this is not the case, and the many studies described in this review demonstrating non-additive effects (both more- and less-than) arising from interactions confirm this.

- Disparity between TEF/RPF values for individual PAHs: For the majority of PAHs data regarding their potency is lacking and therefore many PAHs have not been assigned potency values. A range of RPF or TEF values from 8 different published scales (Collins et al. 1998; EPA 2004; Kroese et al. 2001; Larsen and Larsen 1998; Malcolm and Dobson 1994; Muller 1997; Nisbet and LaGoy 1992; U.S.EPA 2010) is given in Table 4. It is evident from the ranges that there are significant variations in the assigned factors depending on which test systems they are based on that will be reflected when calculating $\mathrm{B}[a] \mathrm{P}_{\mathrm{eq}}$ values for mixtures and is likely to misestimate the risk, in agreement with earlier conclusions about the limitations of equivalency factors (Gaylor et al. 2000; Schneider et al. 2002). Dibenzo[a,l]pyrene is a very good example of this as depending on the scale used the factor can vary between 1 and 100 (Table 4) and has recently been suggested to be even higher (Siddens et al. 2012). Similarly, dibenz[a,h]anthracene ranges from $0.1-10$ suggesting that it is either ten-fold more or less potent than $\mathrm{B}[a] \mathrm{P}$ (Table 4). In many cases these differences can be attributed to the derivation of values from different experimental exposures and cancer studies. However, it remains that the lack of coherence between the different scales is a major limitation for risk assessment.

One of the biggest issues for risk assessment of mixtures of PAHs is the dearth of information available. This lack of information has been highlighted by both the EU and the U.S. EPA as being a significant issue (EC 2009; U.S.EPA 2000). A prioritization of data needs and collection of reliable and relevant data for risk assessment is critical to overcome this issue and a number of 
considerations have been discussed by these agencies previously. Some of the most important considerations are outlined below:

- The need to identify and characterize whole mixtures more extensively and the adoption of procedures to model various human exposure scenarios. Better characterization of the individual PAHs in mixtures is important for understanding their contribution to the mixture and assignment of potency values to more PAHs in mixtures would improve componentbased risk assessment strategies (although this should not predispose risk assessment away from whole mixture analysis).

- Shift towards assessment of whole mixture effects and exposure, including chemicals with dissimilar structures and modes of action. More empirical evidence of the joint action of environmental mixtures would pre-dispose towards more sensitive and accurate risk assessment and likely challenge the rule of thumb assumption that dose addition is sufficient for predicting risk.

- Improvement of the dose-response methods for modelling risk including development of stringent methods for validating these. These models should be robust to include all interaction effects and not just dose addition.

- In many cases mixtures of PAHs have been chosen to suit certain experimental conditions leading to a trend in studying mixtures with known/similar effects and a lack of information on chemicals that alone do not induce effects but can act to modulate toxicity. Future assessment would be better suited by including these chemicals

- Current risk assessment methods tend towards a single risk estimate. A priority towards risk estimate based on exposure ranges would be more appropriate, ideally reflecting different risk analysis methods for the particular mixtures and thus allowing for incorporation of uncertainties associated with method choice.

\subsection{Risk assessment of complex mixtures of PAHs based on whole mixture assessment}


Although the component based approach is recommended and mostly used by both the US and EU authorities, the implementation of a whole mixture based approach is necessary in order to account for possible interaction effects. This has previously been recognized by the U.S. EPA (Flowers et al. 2002; U.S.EPA 2000) and more recently by the US National Toxicology Program (NTP) which has approved a research program aiming to increase the knowledge of complex PAH mixture toxicity (NTP 2012). This approach has so far not been a viable option mainly because of limited data for establishing reference mixtures and methods for determining sufficient similarity.

A potential alternative would be to use mixture assessment factors (MAFs) similar to those that have been discussed previously (Backhaus et al. 2010). In a report for the Swedish Chemicals Agency an approach was discussed outlining how a MAF could be used to reflect a default exposure scenario through single substance assessment for situations where mixtures are present with neither a defined chemical composition (i.e. where it is impossible to ascertain the different components and respective amounts) and where quantitative knowledge regarding individual component toxic potencies is lacking (Backhaus et al. 2010). MAFs, similar to the comparative potency approach, differ to component-based approaches in that they do not rely on individually assigned potency values compared to a reference compound but instead compare the effects of whole mixtures on a relevant biological endpoint. However, in contrast to the comparative potency approach, the MAFs do not rely on a well characterized and sufficiently similar reference mixture but instead on using a well characterized single PAH (i.e. $\mathrm{B}[a] \mathrm{P})$.

We have recently investigated the potential of using activation of DNA damage signaling as a biological end-point for developing MAFs (Jarvis et al. 2013; Niziolek-Kierecka et al. 2012). DNA damage signaling governs the detection of damage and downstream activation of cell cycle arrest, DNA repair and/or cell death and thereby plays an important role in the response to carcinogens 
(Figure 2). Using DNA damage signaling for studying mixtures also has the advantage that whilst the different types of DNA damage induced by PAHs have different kinetics of formation, activate different repair processes, and demonstrate different efficiencies for repair, they share a common DNA damage signaling network directing all of these processes (Ciccia and Elledge 2010; Sancar et al. 2004).

DNA damage signaling results from activation of Ataxia telangiectasia mutated (ATM), ataxia telangiectasia and Rad3-related protein (ATR) or DNA-dependent protein kinase (DNA-PK). Activation of ATM and DNA-PK is commonly attributed to DNA double strand breaks whereas activation of ATR results from single stranded DNA (Lovejoy and Cortez 2009). Two proteins that are activated downstream (by phosphorylation) in the response to the different types of damage are Checkpoint kinase 1 (Chk1), a kinase involved in cell cycle regulation (Zeng et al. 1998; Zhao and Piwnica-Worms 2001) and H2A histone family member $\mathrm{X}$ (H2AX), a core histone protein maintaining genomic stability (Fernandez-Capetillo et al. 2004; Rogakou et al. 1998). Phosphorylation of H2AX is an established marker for DNA damage (Fernandez-Capetillo et al. 2004; Mah et al. 2010) and recent studies of the role of phosphorylated Chk1 in the DNA damage signaling network have confirmed its potential as a marker (Dai and Grant 2010; Ma et al. 2011; Patil et al. 2013). Both proteins have been shown as markers of DNA damage in vivo (Bauer et al. 2011; Bauer et al. 2012) and furthermore have been shown to be activated in response to single and double strand breaks, bulky DNA adducts and oxidative DNA damage, all of which are induced by PAHs as described above (Bihari and Fafandel 2004; Mattsson et al. 2009; Park et al. 2005; Park et al. 2006; Rogan et al. 1993; Szeliga and Dipple 1998; Tung et al. 2014). It is considered that the different types of DNA damage could give rise to different patterns of activation of DNA damage signaling and hence different response proteins. Thus, it is likely necessary that for more accurate risk assessment analysis of more than one marker might be required to cover all the different possible patterns of activation. 
Recently it has been demonstrated that both Chk1 and H2AX are efficiently phosphorylated in response to DNA damage following exposure to low levels of environmental mixtures of PAHs (Jarvis et al. 2013; Mattsson et al. 2009; Niziolek-Kierecka et al. 2012). In a study exposing HepG2 cells to nanomolar concentrations of PAHs extracted from urban air PM persistent phosphorylation of Chk1 and $\mathrm{H} 2 \mathrm{AX}$ was observed at $\mathrm{B}[a] \mathrm{P}_{\mathrm{eq}}$ concentrations of 1 and $8 \mathrm{nM}$ respectively (Jarvis et al. 2013) showing that these markers are sensitive for low levels of DNA damage. Using $\mathrm{B}[a] \mathrm{P}$ as a reference compound the results suggested that the mixture was at least 100 times more potent at $\mathrm{B}[a] \mathrm{P}_{\mathrm{eq}}$ concentrations than exposure to $\mathrm{B}[a] \mathrm{P}$ alone (Jarvis et al. 2013). This is in line with the in vivo studies discussed above (Courter et al. 2008; Courter et al. 2007a; Marston et al. 2001; Siddens et al. 2012) and suggests that phosphorylation of Chk1 and H2AX could serve as biological endpoints for developing MAFs. Further work is required to investigate the effects of exposure to lowlevels of DNA damaging compounds and whether the induction of these markers correlates with results obtained from animal studies.

\subsection{Limitations of the current approaches for PAH mixture risk assessment}

Risk assessment based on whole mixtures is proposed to be more appropriate in future for determining the risks of exposure to PAH mixtures on human health. However, there are a number of issues that have to be considered as outlined below:

- It is impossible to test all mixtures in animal studies. From both an ethical and a practical perspective it is not possible to perform animal studies for every mixture. Analysis of the effects of similar mixtures is a potential way to avoid this issue but that approach is not viable for scenarios where mixture composition changes.

- Challenge to determine what the mixture will be compared against. As environmental mixtures are comprised of many different chemical classes it is a challenge to determine 
how the whole mixtures will be compared experimentally. For example, comparison to $\mathrm{B}[a] \mathrm{P}$ is only sufficient for the $\mathrm{PAH}$ component of the mixture. Furthermore a reliable biological endpoint is required for whole mixture assessment and, although we discuss above how DNA damage signalling is a possibility, it remains to be determined what marker(s) would be most appropriate.

- Chemical characterization is costly and difficult. Whilst it is not fundamentally needed for all whole mixture based risk assessment strategies the characterization of the chemical mixtures for use as a reference mixture (for example in the comparative potency approach) is difficult for a number of reasons including lack of analytical information on individual PAHs for characterization and overlapping of molecular signatures making it hard to analyze low-level PAHs or PAHs with increasing ring numbers.

- Whole mixture assessment does not permit experimental analysis of chemical modes of action. For the purpose of risk assessment this aspect is arguably less important than the above issues. However, important for experimental research is a need to understand the mode of action of chemicals and this is impossible to determine in mixtures, only the mode of action of the mixture is testable.

\section{Conclusions and future challenges for complex PAH mixture risk assessment}

Determining the health risks to humans of exposure to complex $\mathrm{PAH}$ mixtures is profoundly challenging and a daunting task. In this review we have described the current status of the field of mixture effects with regards to PAHs in vitro and in vivo, and why the current approaches for risk assessment are scientifically limited and likely to misestimate the actual risk to human health.

One of the biggest issues for understanding complex PAH mixture toxicity is that it is impossible to test all mixtures in animal models and cultured cell lines. It is widely accepted that both approaches 
have limitations that restrict their extrapolation to human exposures, but at present they remain the best tools for experimental research. It is evident from the studies described in this review that the observed responses to complex PAH mixtures are dependent on the modeling system used. Similar to what the Toxicity Testing in the $21^{\text {st }}$ Century program promotes (NRC 2007; Schmidt 2009) and NTP has recently given approval for (NTP 2012), in the future a combination of different approaches to evaluating complex PAH mixture effects should be used alongside animal models and cultured cell lines to better understand the effects of interactions. This combination could include other approaches such as tissue models generated in bioreactors and human induced pluripotent stem cells, and also in silico modeling, although much more work is required to understand how these can be successfully integrated into risk assessment.

In addition to robust modeling systems, it is necessary to identify reliable, sensitive and relevant markers for risk assessment of complex PAH mixtures which importantly are quantifiable in different experimental settings. The analysis of PAH activation (by CYPs) and study of DNA adduct formation have demonstrated wide variation in the response to complex PAH mixtures (see above described studies) showing they are poor markers for mixture effects. At this point it remains unclear what other markers would be appropriate, though the inclusion of analysis of activation of DNA damage signaling would appear to be compatible.

Finally, the emphasis needs to be switched to studying real life mixtures. It is clear from the above described studies that binary PAH mixture assessment, whilst allowing for general experimental analysis of effects, represents a poor surrogate for studying mixture effects in relation to human risks. An important change for the future and one which has taken precedent in more recent analyses is to investigate the effects of complex PAH mixtures, ideally mixtures that are extracted from actual environmental samples such as urban air and soil. It is important that risk assessment focuses on whole mixtures allowing for the effects of interactions to be included. A greater 
identification of the different chemicals in the mixtures would be beneficial for understanding deposition and human exposure, but should not predispose risk assessment towards componentbased analyses.

In conclusion, it is apparent that there are significant challenges to overcome to implement reliable and accurate risk assessment of complex PAH mixtures. Paramount to this is implementation of analyzing relevant mixtures that reflect actual human exposure. It is important to consider that today no one single approach is reliable or acceptable and that a combination of different techniques and strategies is required. Finally, a concerted effort on behalf of the researchers and the regulatory agencies is required to develop more intelligent and systematic approaches to mixture-based risk assessment.

\section{Acknowledgments}

The work was supported by the Swedish Research Council Formas and Cancer- och Allergifonden.

\section{References}

Albert, R. E., et al. (1983). "Comparative Potency Method for Cancer Risk Assessment: Application to Diesel Particulate Emissions." Risk Analysis 3(2): 101-117.

Alexandrov, K., et al. (2010). "The critical DNA damage by benzo(a)pyrene in lung tissues of smokers and approaches to preventing its formation." Toxicol Lett 198(1): 63-68.

Andrysik, Z., et al. (2011). "Activation of the aryl hydrocarbon receptor is the major toxic mode of action of an organic extract of a reference urban dust particulate matter mixture: the role of polycyclic aromatic hydrocarbons." Mutat Res 714(1-2): 53-62. 
ATSDR (1995). "Toxicological profile for Polycyclic Aromatic Hydrocarbons (PAHs). U.S. Department of Health and Human Services, Public Health Service, Atlanta, GA.".

ATSDR (2004). "Guidance manual for the assessment of joint toxic actions of chemical mixtures.

U.S. Department of Health and Human Services, Public Health Service, Atlanta, GA.".

Backhaus, T., et al. (2010). "Hazard and Risk Assessment of Chemical Mixtures under REACH State of the Art, Gaps and Options for Improvement. Report PM/3 2010. The Swedish National Chemicals Inspectorate, Stockholm, Sweden.".

Baird, W. M., et al. (2005). "Carcinogenic polycyclic aromatic hydrocarbon-DNA adducts and mechanism of action." Environ Mol Mutagen 45(2-3): 106-114.

Bauer, M., et al. (2011). "Human monocytes are severely impaired in base and DNA double-strand break repair that renders them vulnerable to oxidative stress." Proc Natl Acad Sci U S A 108(52): 21105-21110.

Bauer, M., et al. (2012). "Human monocytes undergo excessive apoptosis following temozolomide activating the ATM/ATR pathway while dendritic cells and macrophages are resistant." PLoS One 7(6): e39956.

Beedanagari, S. R., et al. (2010). "Role of epigenetic mechanisms in differential regulation of the dioxin-inducible human CYP1A1 and CYP1B1 genes." Mol Pharmacol 78(4): 608-616.

Bihari, N. and M. Fafandel (2004). "Interspecies differences in DNA single strand breaks caused by benzo(a)pyrene and marine environment." Mutat Res 552(1-2): 209-217.

Binkova, B. and R. J. Sram (2004). "The genotoxic effect of carcinogenic PAHs, their artificial and environmental mixtures (EOM) on human diploid lung fibroblasts." Mutat Res 547(1-2): 109-121.

Boffetta, P., et al. (1997). "Cancer risk from occupational and environmental exposure to polycyclic aromatic hydrocarbons." Cancer Causes Control 8(3): 444-472.

Bollati, V., et al. (2007). "Changes in DNA methylation patterns in subjects exposed to low-dose benzene." Cancer Res 67(3): 876-880. 
Bos, J. L. (1989). "ras Oncogenes in Human Cancer: A Review." Cancer Res 49(17): 4682-4689.

Bosetti, C., et al. (2007). "Occupational exposures to polycyclic aromatic hydrocarbons, and respiratory and urinary tract cancers: a quantitative review to 2005." Ann Oncol 18(3): 431 446.

Boström, C. E., et al. (2002). "Cancer risk assessment, indicators, and guidelines for polycyclic aromatic hydrocarbons in the ambient air." Environ Health Perspect 110 Suppl 3: 451-488.

Bouchard, M., et al. (1998). "Urinary excretion kinetics of 1-hydroxypyrene following intravenous administration of binary and ternary mixtures of polycyclic aromatic hydrocarbons in rat." Arch Toxicol 72(8): 475-482.

Broyde, S., et al. (2010). "Elucidating structure-function relationships in bulky DNA lesions: from solution structures to polymerases. In. The Chemical Biology of DNA Damage Ed. Geacintov, N. \& Broyde, S. Pub. Wiley-VCH."

Budinsky, R. A., et al. (2010). "Human and rat primary hepatocyte CYP1A1 and 1A2 induction with 2,3,7,8-tetrachlorodibenzo-p-dioxin, 2,3,7,8-tetrachlorodibenzofuran, and 2,3,4,7,8pentachlorodibenzofuran." Toxicol Sci 118(1): 224-235.

Buterin, T., et al. (2000). "Unrepaired fjord region polycyclic aromatic hydrocarbon-DNA adducts in ras codon 61 mutational hot spots." Cancer Res 60(7): 1849-1856.

Cherng, S. H., et al. (2006). "Suppressive effect of 1-nitropyrene on benzo[a]pyrene-induced CYP1A1 protein expression in HepG2 cells." Toxicol Lett 161(3): 236-243.

Cherng, S. H., et al. (2001). "Benzo[g,h,i]perylene synergistically transactivates benzo[a]pyreneinduced CYP1A1 gene expression by aryl hydrocarbon receptor pathway." Toxicol Appl Pharmacol 170(1): 63-68.

Chou, M. W. and P. P. Fu (1983). "Evidence for the metabolic formation of a vicinal dihydrodiolepoxide from the potent mutagen 1-nitrobenzo(A)pyrene." Biochem Biophys Res Commun 117(2): $541-548$ 
Chuang, J. C., et al. (1992). "Chemical characterization of mutagenic fractions of particles from indoor coal combustion: a study of lung cancer in Xuan Wei, China." Environ Sci Technol 26(5): 999-1004.

Ciccia, A. and S. J. Elledge (2010). "The DNA damage response: making it safe to play with knives." Mol Cell 40(2): 179-204.

Claxton, L. D., et al. (2004). "The genotoxicity of ambient outdoor air, a review: Salmonella mutagenicity." Mutat Res 567(2-3): 347-399.

Collins, J. F., et al. (1998). "Potency equivalency factors for some polycyclic aromatic hydrocarbons and polycyclic aromatic hydrocarbon derivatives." Regul Toxicol Pharmacol 28(1): $45-54$.

Conney, A. H. (1982). "Induction of microsomal enzymes by foreign chemicals and carcinogenesis by polycyclic aromatic hydrocarbons: G. H. A. Clowes Memorial Lecture." Cancer Res 42(12): 4875-4917.

Courter, L. A., et al. (2008). "The influence of diesel exhaust on polycyclic aromatic hydrocarboninduced DNA damage, gene expression, and tumor initiation in Sencar mice in vivo." Cancer Lett 265(1): 135-147.

Courter, L. A., et al. (2007a). "Urban dust particulate matter alters PAH-induced carcinogenesis by inhibition of CYP1A1 and CYP1B1." Toxicol Sci 95(1): 63-73.

Courter, L. A., et al. (2007b). "Diesel exhaust influences carcinogenic PAH-induced genotoxicity and gene expression in human breast epithelial cells in culture." Mutat Res 625(1-2): 72-82.

Culp, S. J., et al. (1998). "A comparison of the tumors induced by coal tar and benzo[a]pyrene in a 2-year bioassay." Carcinogenesis 19(1): 117-124.

Dai, Y. and S. Grant (2010). "New insights into checkpoint kinase 1 in the DNA damage response signaling network." Clin Cancer Res 16(2): 376-383.

DeMarini, D. M. (2004). "Genotoxicity of tobacco smoke and tobacco smoke condensate: a review." Mutat Res 567(2-3): 447-474. 
DeMarini, D. M., et al. (2001). "Lung tumor KRAS and TP53 mutations in nonsmokers reflect exposure to PAH-rich coal combustion emissions." Cancer Res 61(18): 6679-6681.

Deutsch-Wenzel, R. P., et al. (1984). "Investigation on the carcinogenicity of emission condensate from brown coal-fired residential furnaces applied to mouse skin." Cancer Lett 25(1): 103111.

DiGiovanni, J., et al. (1982). "Anticarcinogenic and cocarcinogenic effects of benzo[e]pyrene and dibenz[a,c]anthracene on skin tumor initiation by polycyclic hydrocarbons." $\underline{\text { Carcinogenesis }}$ 3(4): $371-375$.

Dipple, A., et al. (1987). "Optically active benzo[c]phenanthrene diol epoxides bind extensively to adenine in DNA." Nature 327(6122): 535-536.

Djuric, Z., et al. (1986). "Oxidative microsomal metabolism of 1-nitropyrene and DNA-binding of oxidized metabolites following nitroreduction." Carcinogenesis 7(7): 1073-1079.

Dreij, K., et al. (2005). "Differential removal of DNA adducts derived from anti-diol epoxides of dibenzo[a,1]pyrene and benzo[a]pyrene in human cells." Chem Res Toxicol 18(4): 655-664.

EC (2009). "State of the Art Report on Mixture Toxicity."

ECETOC (2003). "Derivation of assessment factors for human health risk assessment (TR 86). European Centre for Ecotoxicology and Toxicology of Chemicals, Brussels.".

ECETOC (2010). "Guidance on assessment factors to derive a DNEL (TR 110). European Centre for Ecotoxicology and Toxicology of Chemicals, Brussels.".

EFSA (2008). "Scientific Opinion of the Panel on Contaminants in the Food Chain on a request from the European Commission on Polycyclic Aromatic Hydrocarbons in Food." The EFSA Journal 724: 1-114.

Eoff, R. L., et al. (2010). "Impact of chemical adducts on tranlesion synthesis in replicative and bypass DNA polymerases: From structure to function. In. The Chemical Biology of DNA Damage Ed. Geacintov, N. \& Broyde, S. Pub. Wiley-VCH." 
EPA (2004). "No Significant Risk Levels (NSRLs) for the Proposition 65 carcinogens benzo[b]fluoranthene, benzo[j]fluoranthene, chrysene, dibenzo[a,h]pyrene, dibenzo[a,i]pyrene, and 5-methylchrysene by the oral route. Office of Environmental Health Hazard Assessment, Reproductive and Cancer Hazard Assessment Section, Oakland, CA.". Esteller, M. (2008). "Epigenetics in cancer." N Engl J Med 358(11): 1148-1159.

Falahatpisheh, M., et al. (2004). "Inducible cytochrome P450 activities in renal glomerular mesangial cells: biochemical basis for antagonistic interactions among nephrocarcinogenic polycyclic aromatic hydrocarbons." J Carcinog 3(1): 12.

Fernandez-Capetillo, O., et al. (2004). "H2AX: the histone guardian of the genome." DNA Repair (Amst) 3(8-9): 959-967.

Flowers, L., et al. (2002). "Health Assessment of Polycyclic Aromatic Hydrocarbon Mixtures: Current Practices and Future Directions." Polycyclic Aromatic Compounds 22(3-4): 811821.

Gabelova, A., et al. (2013). "Sustained induction of cytochrome P4501A1 in human hepatoma cells by co-exposure to benzo[a]pyrene and 7H-dibenzo[c,g]carbazole underlies the synergistic effects on DNA adduct formation." Toxicol Appl Pharmacol 271(1): 1-12.

Gaylor, D. W., et al. (2000). "Cancer risk estimation for mixtures of coal tars and benzo(a)pyrene." Risk Anal 20(1): 81-85.

Goldstein, L. S., et al. (1998). "Tumors and DNA adducts in mice exposed to benzo[a]pyrene and coal tars: implications for risk assessment." Environ Health Perspect 106 Suppl 6: 13251330.

Gray, D. L., et al. (2001). "The effects of a binary mixture of benzo(a)pyrene and 7Hdibenzo(c,g)carbazole on lung tumors and K-ras oncogene mutations in strain A/J mice." Exp Lung Res 27(3): 245-253. 
Grimmer, G., et al. (1988). "Contribution of polycyclic aromatic compounds to the carcinogenicity of sidestream smoke of cigarettes evaluated by implantation into the lungs of rats." Cancer Lett 43(3): 173-177.

Grimmer, G., et al. (1987a). "Contribution of polycyclic aromatic hydrocarbons and nitroderivatives to the carcinogenic impact of diesel engine exhaust condensate evaluated by implantation into the lungs of rats." Cancer Lett 37(2): 173-180.

Grimmer, G., et al. (1987b). "Contribution of polycyclic aromatic hydrocarbons and polar polycyclic aromatic compounds to the carcinogenic impact of flue gas condensate from coal-fired residential furnaces evaluated by implantation into the rat lung." $\mathrm{J}$ Natl Cancer Inst 78(5): 935-942.

Grimmer, G., et al. (1984). "The contribution of polycyclic aromatic hydrocarbons to the carcinogenic impact of emission condensate from coal-fired residential furnaces evaluated by topical application to the skin of mice." Cancer Lett 23(2): 167-176.

Grimmer, G., et al. (1985). "The contribution of polycyclic aromatic hydrocarbon fractions with different boiling ranges to the carcinogenic impact of emission condensate from coal fired residential furnaces as evaluated by topical application to the skin of mice." $\underline{\text { Cancer Lett }}$ 28(2): 203-211.

Grimmer, G., et al. (1983). "On the contribution of polycyclic aromatic hydrocarbons to the carcinogenic impact of automobile exhaust condensate evaluated by local application onto mouse skin." Cancer Lett 21(1): 105-113.

Grimmer, G., et al. (1982). "Quantification of the carcinogenic effect of polycyclic aromatic hydrocarbons in used engine oil by topical application onto the skin of mice." Int Arch Occup Environ Health 50(1): 95-100.

Hainaut, P., et al. (1998). "IARC Database of p53 gene mutations in human tumors and cell lines: updated compilation, revised formats and new visualisation tools." Nucleic Acids Res 26(1): 205-213. 
Harris, K. L., et al. (2013). "Benzo(a)pyrene modulates fluoranthene-induced cellular responses in HT-29 colon cells in a dual exposure system." Environ Toxicol Pharmacol 36(2): 358-367.

Henry, E. C. and T. A. Gasiewicz (2008). "Molecular determinants of species-specific agonist and antagonist activity of a substituted flavone towards the aryl hydrocarbon receptor." $\underline{\text { Arch }}$ Biochem Biophys 472(2): 77-88.

Hollstein, M., et al. (1991). "p53 Mutations in Human Cancers." Science 253(5015): 49-53.

Howsam, M. and K. C. Jones (1998). "Sources of PAHs in the Environment. In. PAHs and Related Compounds: The Handbook of Environmental Chemistry Volume 3 / 3I, pp 137-174."

Huang, X., et al. (2003). "Effects of base sequence context on translesion synthesis past a bulky (+)trans-anti-B[a]P-N2-dG lesion catalyzed by the Y-family polymerase pol kappa." Biochemistry 42(8): 2456-2466.

Huang, Y. C. (2013). "The role of in vitro gene expression profiling in particulate matter health research." J Toxicol Environ Health B Crit Rev 16(6): 381-394.

Huberman, E., et al. (1976). "Identification of mutagenic metabolites of benzo(a)pyrene in mammalian cells." Proc Natl Acad Sci U S A 73(2): 607-611.

Hughes, N. C. and D. H. Phillips (1990). "Covalent binding of dibenzpyrenes and benzo[a]pyrene to DNA: evidence for synergistic and inhibitory interactions when applied in combination to mouse skin." Carcinogenesis 11(9): 1611-1619.

Hussain, S. P., et al. (2001). "Mutability of p53 hotspot codons to benzo(a)pyrene diol epoxide (BPDE) and the frequency of p53 mutations in nontumorous human lung." $\underline{\text { Cancer Res }}$ 61(17): 6350-6355.

IARC (2004). "Tobacco Smoke and Involuntary Smoking. IARC Monographs on the Evaluation of Carcinogenic Risks to Humans Volume 83. IARC Press."

IARC (2010). "Some Non-Heterocyclic Polycyclic Aromatic Hydrocarbons and Some Related Exposures. IARC Monographs on the Evaluation of Carcinogenic Risks to Humans Volume 92. IARC Press." 
IPCS (1998). "Selected Non-heterocyclic Polycyclic Aromatic Hydrocarbons. Environmental Health Criteria 202. International Programme on Chemical Safety, World Health Organization, Geneva.".

IPCS (2009). "Assessment of combined exposures to multiple chemicals: Report of a WHO/IPCS international workshop."

Jarvis, I. W., et al. (2013). "Persistent activation of DNA damage signaling in response to complex mixtures of PAHs in air particulate matter." Toxicol Appl Pharmacol 266(3): 408-418.

Jerina, D. M., et al. (1986). "Reactivity and tumorigenicity of bay-region diol epoxides derived from polycyclic aromatic hydrocarbons." Adv Exp Med Biol 197: 11-30.

Jones, P. A. and S. B. Baylin (2007). "The epigenomics of cancer." Cell 128(4): 683-692.

KEMI (2003). "Proposals for the use of assessment (uncertainty) factors - application to risk assessment for plant protection products, industrial chemicals and biocidal products within the European union No 1/03. The Swedish National Chemicals Inspectorate, Stockholm, Sweden.".

Knasmuller, S., et al. (1998). "Use of metabolically competent human hepatoma cells for the detection of mutagens and antimutagens." Mutat Res 402(1-2): 185-202.

Kroese, E. D., et al. (2001). "Tumorigenic effects in Wistar rats orally administered benzo[a]pyrene for two years (gavage studies). Implications for human cancer risks associated with oral exposure to polycyclic aromatic hydrocarbons. National Institute of Public Health and the Environment, Bilthoven, Netherlands.".

Kropachev, K., et al. (2013). "Adenine-DNA adducts derived from the highly tumorigenic Dibenzo[a,l]pyrene are resistant to nucleotide excision repair while guanine adducts are not." Chem Res Toxicol 26(5): 783-793.

Kuljukka-Rabb, T., et al. (2001). "Time- and dose-dependent DNA binding of PAHs derived from diesel particle extracts, benzo[a]pyrene and 5-methychrysene in a human mammary carcinoma cell line (MCF-7)." Mutagenesis 16(4): 353-358. 
Larsen, J. C. and P. B. Larsen (1998). ""Chemical Carcinogens" in Air Pollution and Health. Issues in Environmental Science and Technology. Ed. Hester, R. E. and Harrison, R. M. Pub. The Royal Society of Chemistry."

Lewtas, J. (1985). "Development of a comparative potency method for cancer risk assessment of complex mixtures using short-term in vivo and in vitro bioassays." Toxicol Ind Health 1(4): 193-203.

Lodovici, M. and E. Bigagli (2011). "Oxidative stress and air pollution exposure." J Toxicol 2011: 487074.

Lovejoy, C. A. and D. Cortez (2009). "Common mechanisms of PIKK regulation." DNA Repair (Amst) 8(9): 1004-1008.

Ma, C. X., et al. (2011). "Death by releasing the breaks: CHK1 inhibitors as cancer therapeutics." Trends Mol Med 17(2): 88-96.

Mah, L. J., et al. (2010). "gammaH2AX: a sensitive molecular marker of DNA damage and repair." Leukemia 24(4): 679-686.

Mahadevan, B., et al. (2005a). "Altered gene expression patterns in MCF-7 cells induced by the urban dust particulate complex mixture standard reference material 1649a." $\underline{\text { Cancer Res }}$ 65(4): 1251-1258.

Mahadevan, B., et al. (2005b). "Effect of a standardized complex mixture derived from coal tar on the metabolic activation of carcinogenic polycyclic aromatic hydrocarbons in human cells in culture." Chem Res Toxicol 18(2): 224-231.

Mahadevan, B., et al. (2007). "Competitive inhibition of carcinogen-activating CYP1A1 and CYP1B1 enzymes by a standardized complex mixture of PAH extracted from coal tar." Int J Cancer 120(6): 1161-1168.

Malcolm, H. M. and S. Dobson (1994). "The calculation of an environmental assessment level (EAL) for atmospheric PAHs using relative potencies. Report No. DoE/HMIP/RR/94/041. Department of the Environment, London, England.". 
Marston, C. P., et al. (2001). "Effect of a complex environmental mixture from coal tar containing polycyclic aromatic hydrocarbons (PAH) on the tumor initiation, PAH-DNA binding and metabolic activation of carcinogenic PAH in mouse epidermis." Carcinogenesis 22(7): 1077-1086.

Martin, O. V., et al. (2013). "Dispelling urban myths about default uncertainty factors in chemical risk assessment -- sufficient protection against mixture effects?" Environ Health 12(1): 53.

Mason, J. M., et al. (1990). "Ability of short-term tests to predict carcinogenesis in rodents." Annu Rev Pharmacol Toxicol 30: 149-168.

Mattsson, A., et al. (2009). "Exposure of HepG2 cells to low levels of PAH-containing extracts from contaminated soils results in unpredictable genotoxic stress responses." Environ Mol Mutagen 50(4): 337-348.

Mauderly, J. L. (1993). "Toxicological approaches to complex mixtures." Environ Health Perspect 101 Suppl 4: 155-165.

May, W. E., et al. (1992). "Standard reference materials for chemical and biological studies of complex environmental samples." Mutat Res 276(1-2): 11-22.

McCoull, K. D., et al. (1999). "Synthesis and characterization of polycyclic aromatic hydrocarbon o-quinone depurinating N7-guanine adducts." Chem Res Toxicol 12(3): 237-246.

Mordukhovich, I., et al. (2010). "Associations between polycyclic aromatic hydrocarbon-related exposures and p53 mutations in breast tumors." Environ Health Perspect 118(4): 511-518.

Muller, P. (1997). "Scientific Criteria Document for Multimedia Standards Development, Polycyclic Aromatic Hydrocarbons (PAH). Part 1, Hazard Identification and Dose-response Assessment : Report. Standards Development Branch, Ontario Ministry of Environment and Energy."

Musafia-Jeknic, T., et al. (2005). "Long-term effects of a standardized complex mixture of urban dust particulate on the metabolic activation of carcinogenic polycyclic aromatic hydrocarbons in human cells in culture." Toxicol Sci 88(2): 358-366. 
Nebert, D. W., et al. (2004). "Role of aryl hydrocarbon receptor-mediated induction of the CYP1 enzymes in environmental toxicity and cancer." J Biol Chem 279(23): 23847-23850.

Nesnow, S., et al. (1998). "Lung tumorigenic interactions in strain A/J mice of five environmental polycyclic aromatic hydrocarbons." Environ Health Perspect 106 Suppl 6: 1337-1346.

Nesnow, S., et al. (1983). "Mouse skin tumor initiation-promotion and complete carcinogenesis bioassays: mechanisms and biological activities of emission samples." Environ Health Perspect 47: 255-268.

Nisbet, I. C. and P. K. LaGoy (1992). "Toxic equivalency factors (TEFs) for polycyclic aromatic hydrocarbons (PAHs)." Regul Toxicol Pharmacol 16(3): 290-300.

Niziolek-Kierecka, M., et al. (2012). "gammaH2AX, pChk1, and Wip1 as Potential Markers of Persistent DNA Damage Derived from Dibenzo[a,1]pyrene and PAH-Containing Extracts from Contaminated Soils." Chem Res Toxicol 25(4): 862-872.

NRC (2007). "National Research Council. Toxicity Testing in the 21st Century: A Vision and a Strategy. The National Academies Press, Washington, DC.".

NTP (2012). "NTP Research Concept: Polycyclic Aromatic Hydrocarbons (PAHs) - Draft: NTP Board of Scientific Counselors Meeting."

Oh, S. M., et al. (2011). "Organic extracts of urban air pollution particulate matter (PM2.5)-induced genotoxicity and oxidative stress in human lung bronchial epithelial cells (BEAS-2B cells)." Mutat Res 723(2): 142-151.

Ohe, T., et al. (2004). "Mutagens in surface waters: a review." Mutat Res 567(2-3): 109-149.

Park, J. H., et al. (2005). "Formation of 8-oxo-7,8-dihydro-2'-deoxyguanosine (8-oxo-dGuo) by PAH o-quinones: involvement of reactive oxygen species and copper(II)/copper(I) redox cycling." Chem Res Toxicol 18(6): 1026-1037.

Park, J. H., et al. (2008). "Evidence for the aldo-keto reductase pathway of polycyclic aromatic trans-dihydrodiol activation in human lung A549 cells." Proc Natl Acad Sci U S A 105(19): 6846-6851. 
Park, J. H., et al. (2006). "Polycyclic aromatic hydrocarbon (PAH) o-quinones produced by the aldo-keto-reductases (AKRs) generate abasic sites, oxidized pyrimidines, and 8-oxo-dGuo via reactive oxygen species." Chem Res Toxicol 19(5): 719-728.

Patil, M., et al. (2013). "Checkpoint kinase 1 in DNA damage response and cell cycle regulation." Cell Mol Life Sci 70(21): 4009-4021.

Pavanello, S., et al. (2009). "Global and gene-specific promoter methylation changes are related to anti-B[a]PDE-DNA adduct levels and influence micronuclei levels in polycyclic aromatic hydrocarbon-exposed individuals." Int J Cancer 125(7): 1692-1697.

Pavanello, S., et al. (2010). "Shorter telomere length in peripheral blood lymphocytes of workers exposed to polycyclic aromatic hydrocarbons." Carcinogenesis 31(2): 216-221.

Pelkonen, O. and D. W. Nebert (1982). "Metabolism of polycyclic aromatic hydrocarbons: etiologic role in carcinogenesis." Pharmacol Rev 34(2): 189-222.

Penning, T. M., et al. (1999). "Dihydrodiol dehydrogenases and polycyclic aromatic hydrocarbon activation: generation of reactive and redox active o-quinones." Chem Res Toxicol 12(1): 118.

Pereira, M. A. (1982). "Skin tumorigenesis research data base." J Am Coll Toxicol 1: 47-82.

Peters, A., et al. (2001). "Increased particulate air pollution and the triggering of myocardial infarction." Circulation 103(23): 2810-2815.

Phillips, D. H. (1999). "Polycyclic aromatic hydrocarbons in the diet." Mutat Res 443(1-2): 139147.

Pohjola, S. K., et al. (2003). "DNA binding of polycyclic aromatic hydrocarbons in a human bronchial epithelial cell line treated with diesel and gasoline particulate extracts and benzo[a]pyrene." Mutagenesis 18(5): 429-438.

Pope, C. A., 3rd, et al. (2002). "Lung cancer, cardiopulmonary mortality, and long-term exposure to fine particulate air pollution." JAMA 287(9): 1132-1141. 
Prior, I. A., et al. (2012). "A comprehensive survey of Ras mutations in cancer." Cancer Res 72(10): 2457-2467.

Pufulete, M., et al. (2004). "Approaches to carcinogenic risk assessment for polycyclic aromatic hydrocarbons: a UK perspective." Regul Toxicol Pharmacol 40(1): 54-66.

Ralston, S. L., et al. (1995). "Stereoselective activation of dibenzo[a,1]pyrene to (-)-anti (11R,12S,13S,14R)- and (+)-syn(11S,12R,13S,14R)-11,12-diol-13,14-epoxides which bind extensively to deoxyadenosine residues of DNA in the human mammary carcinoma cell line MCF-7." Carcinogenesis 16(12): 2899-2907.

Ravindra, K., et al. (2008). "Atmospheric polycyclic aromatic hydrocarbons: Source attribution, emission factors and regulation." Atmospheric Environment 42(13): 2895-2921.

Rice, J. E., et al. (1988). "The influence of fluoranthene on the metabolism and DNA binding of benzo[a]pyrene in vivo in mouse skin." Chem Biol Interact 68(1-2): 127-136.

Rice, J. E., et al. (1984). "Fluoranthene and pyrene enhance benzo[a]pyrene--DNA adduct formation in vivo in mouse skin." Cancer Lett 24(3): 327-333.

Robinson, M., et al. (1987). "Carcinogenic effects in A/J mice of particulate of a coal tar paint used in potable water systems." Cancer Lett 34(1): 49-54.

Rogakou, E. P., et al. (1998). "DNA double-stranded breaks induce histone H2AX phosphorylation on serine 139." J Biol Chem 273(10): 5858-5868.

Rogan, E. G., et al. (1993). "Identification and quantitation of benzo[a]pyrene-DNA adducts formed in mouse skin." Chem Res Toxicol 6(3): 356-363.

Ross, J. A. and S. Nesnow (1999). "Polycyclic aromatic hydrocarbons: correlations between DNA adducts and ras oncogene mutations." Mutat Res 424(1-2): 155-166.

Rossner, P., Jr., et al. (2013). "Nucleotide excision repair is not induced in human embryonic lung fibroblasts treated with environmental pollutants." PLoS One 8(7): e69197.

Sancar, A., et al. (2004). "Molecular mechanisms of mammalian DNA repair and the DNA damage checkpoints." Annu Rev Biochem 73: 39-85. 
SCHER, et al. (2012). "Opinion on the Toxicity and Assessment of Chemical Mixtures."

Schmidt, C. W. (2009). "TOX 21: new dimensions of toxicity testing." Environ Health Perspect 117(8): A348-353.

Schneider, K., et al. (2002). "Cancer risk assessment for oral exposure to PAH mixtures." J Appl Toxicol 22(1): 73-83.

Sen, B., et al. (2007). "Transcriptional responses to complex mixtures: a review." Mutat Res 636(13): 144-177.

Sevastyanova, O., et al. (2007). "In vitro genotoxicity of PAH mixtures and organic extract from urban air particles part II: human cell lines." Mutat Res 620(1-2): 123-134.

Shimada, T. and Y. Fujii-Kuriyama (2004). "Metabolic activation of polycyclic aromatic hydrocarbons to carcinogens by cytochromes P450 1A1 and 1B1." Cancer Sci 95(1): 1-6.

Shimada, T., et al. (1996). "Activation of chemically diverse procarcinogens by human cytochrome P-450 1B1." Cancer Res 56(13): 2979-2984.

Shou, M., et al. (1993). "Reactivity of benzo[a]pyrene-7,8-dione with DNA. Evidence for the formation of deoxyguanosine adducts." Carcinogenesis 14(3): 475-482.

Siddens, L. K., et al. (2012). "Polycyclic aromatic hydrocarbons as skin carcinogens: comparison of benzo[a]pyrene, dibenzo[def,p]chrysene and three environmental mixtures in the FVB/N mouse." Toxicol Appl Pharmacol 264(3): 377-386.

Silkworth, J. B., et al. (2005). "Comparison of TCDD and PCB CYP1A induction sensitivities in fresh hepatocytes from human donors, sprague-dawley rats, and rhesus monkeys and HepG2 cells." Toxicol Sci 87(2): 508-519.

Sims, P. and P. L. Grover (1974). "Epoxides in polycyclic aromatic hydrocarbon metabolism and carcinogenesis." Adv Cancer Res 20: 165-274.

Sims, P., et al. (1974). "Metabolic activation of benzo(a)pyrene proceeds by a diol-epoxide." Nature 252(5481): 326-328. 
Slaga, T. J., et al. (1979). "The effects of weak or non-carcinogenic polycyclic hydrocarbons on 7,12-dimethylbenz[a]anthracene and benzo[a]pyrene skin tumor-initiation." $\underline{\text { Cancer Lett }}$ 7(1): 51-59.

Smolarek, T. A. and W. M. Baird (1984). "Benzo[e]pyrene-induced alterations in the binding of benzo[a]pyrene to DNA in hamster embryo cell cultures." Carcinogenesis 5(8): 1065-1069.

Smolarek, T. A., et al. (1987). "Benzo(e)pyrene-induced alterations in the binding of benzo(a)pyrene and 7,12-dimethylbenz(a)anthracene to DNA in Sencar mouse epidermis." Cancer Res 47(14): 3701-3706.

Staal, Y. C. M., et al. (2007). "Binary PAH mixtures cause additive or antagonistic effects on gene expression but synergistic effects on DNA adduct formation." Carcinogenesis 28(12): 26322640.

Staal, Y. C. M., et al. (2008). "Interactions between polycyclic aromatic hydrocarbons in binary mixtures: Effects on gene expression and DNA adduct formation in precision-cut rat liver slices." Mutagenesis 23(6): 491-499.

Suh, M., et al. (1995). "Formation and persistence of benzo[a]pyrene-DNA adducts in mouse epidermis in vivo: importance of adduct conformation." Carcinogenesis 16(10): 2561-2569.

Szeliga, J. and A. Dipple (1998). "DNA adduct formation by polycyclic aromatic hydrocarbon dihydrodiol epoxides." Chem Res Toxicol 11(1): 1-11.

Tarantini, A., et al. (2009). "Relative contribution of DNA strand breaks and DNA adducts to the genotoxicity of benzo[a]pyrene as a pure compound and in complex mixtures." Mutat Res 671(1-2): 67-75.

Tarantini, A., et al. (2011). "Polycyclic aromatic hydrocarbons in binary mixtures modulate the efficiency of benzo[a]pyrene to form DNA adducts in human cells." Toxicology 279: 36-44.

Tobiszewski, M. and J. Namieśnik (2012). "PAH diagnostic ratios for the identification of pollution emission sources." Environmental Pollution 162: 110-119. 
Tung, E. W., et al. (2014). "Benzo[a]pyrene increases DNA double strand break repair in vitro and in vivo: a possible mechanism for benzo[a]pyrene-induced toxicity." Mutat Res 760: 64-69.

U.S.EPA (2000). "Supplementary Guidance for Conducting Health Risk Assessment of Chemical Mixtures (EPA/630/R-00/002). U.S. Environmental Protection Agency, Washington, DC.".

U.S.EPA (2007). "Concepts, Methods and Data Sources for Cumulative Health Risk Assessment of Multiple Chemicals, Exposures and Effects: A Resource Document (EPA/600/R-06/013F). U.S. Environmental Protection Agency, Washington, DC.".

U.S.EPA (2010). "Development of a Relative Potency Factor (RPF) Approach for Polycyclic Aromatic Hydrocarbon (PAH) Mixtures (External Review Draft, EPA/635/R-08/012A). U.S. Environmental Protection Agency, Washington, DC.".

Van Tiem, L. A. and R. T. Di Giulio (2011). "AHR2 knockdown prevents PAH-mediated cardiac toxicity and XRE- and ARE-associated gene induction in zebrafish (Danio rerio)." Toxicol Appl Pharmacol 254(3): 280-287.

Weyand, E. H., et al. (1995). "Differences in the tumorigenic activity of a pure hydrocarbon and a complex mixture following ingestion: benzo[a]pyrene vs manufactured gas plant residue." Chem Res Toxicol 8(7): 949-954.

White, P. A. (2002). "The genotoxicity of priority polycyclic aromatic hydrocarbons in complex mixtures." Mutat Res 515(1-2): 85-98.

White, P. A. and L. D. Claxton (2004). "Mutagens in contaminated soil: a review." Mutat Res 567(2-3): 227-345.

WHO (2000). "Air Quality Guidelines for Europe, Second Edition; World Health Organization (WHO) Regional Office for Europe: Copenhagen, Denmark.".

Willett, K. L., et al. (2001). "In vivo and in vitro inhibition of CYP1A-dependent activity in Fundulus heteroclitus by the polynuclear aromatic hydrocarbon fluoranthene." Toxicol Appl Pharmacol 177(3): 264-271. 
Yauk, C., et al. (2008). "Germ-line mutations, DNA damage, and global hypermethylation in mice exposed to particulate air pollution in an urban/industrial location." Proc Natl Acad Sci U S A 105(2): 605-610.

Zeng, Y., et al. (1998). "Replication checkpoint requires phosphorylation of the phosphatase Cdc25 by Cds1 or Chk1." Nature 395(6701): 507-510.

Zhang, L., et al. (2012). "The Role of Human Aldo-Keto Reductases in the Metabolic Activation and Detoxication of Polycyclic Aromatic Hydrocarbons: Interconversion of PAH Catechols and PAH o-Quinones." Front Pharmacol 3: 193.

Zhao, H. and H. Piwnica-Worms (2001). "ATR-mediated checkpoint pathways regulate phosphorylation and activation of human Chk1." Mol Cell Biol 21(13): 4129-4139. 


\section{Figure Legends}

Figure 1. Examples of some commonly studied PAHs (A) and substituted PAHs (B). The bay and fjord regions are indicated by arrows.

\section{Figure 2. DNA damage signalling coordinates the genotoxic insults caused by complex PAH} mixtures. A large variety of DNA damages including strand breaks, adduct formation, oxidative damage and abasic sites resulting from depurinating damages occur following exposure to complex PAH mixtures. Central to the response to these damage stimuli is DNA damage signalling. Tolerable DNA damage can lead to downstream responses including cell cycle arrest and DNA repair, whereas excessive/irreparable DNA damage can lead to apoptosis. Both scenarios are considered positive responses as they prevent the carcinogenic process. Mutations can occur as a result of unrepaired or wrongly repaired DNA damage or errors in signal transduction and are a negative outcome as they promote and accelerate the carcinogenic process. The pivotal role that DNA damage signalling plays in coordinating the DNA damage response makes it an appropriate biological endpoint for whole mixture assessment. 
Table 1: Summary of the effects on CYP450s and DNA adduct formation after in vivo and in vitro exposure to binary PAH mixtures compared to individual PAH effects

\begin{tabular}{|c|c|c|c|c|c|c|c|c|}
\hline \multirow{2}{*}{ Test System } & \multirow{2}{*}{ PAH Mixture } & \multirow{2}{*}{ Dose } & \multirow{2}{*}{ Route } & \multicolumn{3}{|c|}{ CYP450s } & \multirow{2}{*}{ Adduct Levels } & \multirow{2}{*}{ Reference } \\
\hline & & & & Studied & EROD & Effect & & \\
\hline \multicolumn{9}{|c|}{ In vivo studies } \\
\hline \multirow{4}{*}{ Female CD-1 Mice } & $\mathrm{B}[a] \mathrm{P}: \mathrm{B}[e] \mathrm{P} / \mathrm{PYR} / \mathrm{FLU}$ & $200^{\mathrm{a}}: 100^{\mathrm{b}}$ & Topical & & & & + & \\
\hline & DMBA:B $[e] \mathrm{P}$ & $10^{\mathrm{a}}: 100^{\mathrm{b}}$ & Topical & & & & - & Slaga et al. 1979 \\
\hline & B[a]PFLUTPYR & $15-22^{a}=171-183^{a-}$ & Topical & & & & + & Rice et al. 1984 \\
\hline & $\mathrm{B}[a] \mathrm{P}: \mathrm{FLU}$ & $11^{\mathrm{a}}: 110^{\mathrm{a}}$ & Topical & & & & + & Rice et al. 1988 \\
\hline \multirow{4}{*}{ Female SENCAR Mice } & $\mathrm{B}[a] \mathrm{P}: \mathrm{B}[e] \mathrm{P}$ & $200: 20-200^{\mathrm{a}}$ & Topical & & & & $=$ & DiGiovanni et al 1982 \\
\hline & DMBA:B $[e] P$ & $20: 20-200^{\mathrm{a}}$ & Topical & & & & + & DiGiovanni et al. 1982 \\
\hline & $\mathrm{B}[a] \mathrm{P}: \mathrm{B}[e] \mathrm{P}$ & $50-200: 50-2000^{\mathrm{a}}$ & Topical & & & & + & \\
\hline & DMBA:B $[e] \mathrm{P}$ & $5-20: 5-400^{\mathrm{a}}$ & Topical & & & & - & Smolarek et al. 1987 \\
\hline \multirow{3}{*}{ Male Parkes Mice } & $\mathrm{DB}[a, l] \mathrm{P}: \mathrm{B}[a] \mathrm{P} / \mathrm{DB}[a, e] \mathrm{P}$ & $500: 500^{a}$ & Topical & & & & $=$ & \\
\hline & $\mathrm{B}[a] \mathrm{P}: \mathrm{DB}[a, e] \mathrm{P}$ & $500: 500^{\mathrm{a}}$ & Topical & & & & + & Hughes and Phillips 1990 \\
\hline & $\mathrm{DB}[a, l] \mathrm{P}: \mathrm{B}[a] \mathrm{P}: \mathrm{DB}[a, e] \mathrm{P}$ (tertiary mixture) & $500: 500: 500^{\mathrm{a}}$ & Topical & & & & - & \\
\hline \multirow{2}{*}{ Male Sprague-Dawley Rats } & PYR:B $[a] \mathrm{P}$ & $5: 0.5-25^{\mathrm{c}}$ & i.v. & & No & $+(\mathrm{met})$ & & \\
\hline & PYR:NAP & $5: 0.5-25^{\mathrm{c}}$ & i.v. & & No & + (met) & & Bouchard et al. 1998 \\
\hline Fundulus heteroclitus & $\mathrm{B}[a] \mathrm{P}: \mathrm{FLU}$ & $5: 5-50^{\mathrm{d}^{--}}$ & i.p. & $1 \mathrm{~A}$ & Y̌es & $-(\mathrm{act})$ &,+- & Willett et al. 2001 \\
\hline Danio rerio & $\mathrm{B}[k] \mathrm{F}: \mathrm{FLU}$ & $50: 150^{\mathrm{e}}$ & & $1 \mathrm{~A}, 1 \mathrm{~B} 1,1 \mathrm{C} 1$ & Yes & $+(\exp ),-(\mathrm{act})$ & & Van Tiem and Di Giulio 2011 \\
\hline \multicolumn{9}{|c|}{ In vitro studies } \\
\hline \multirow{8}{*}{ HepG2 cells (human) } & $\mathrm{B}[a] \mathrm{P}: \mathrm{B}[g h i] \mathrm{P}$ & $1: 0.1-10^{f}$ & & $1 \mathrm{~A} 1$ & No & $+(\exp )$ & + & Cherng et al. 2001 \\
\hline & $\mathrm{B}[a] \mathrm{P}: 1-\mathrm{NP}$ & $10: 2.5-10^{1}$ & & $1 \mathrm{~A} 1$ & No & $-(\exp )$ & - & Cherng et al. 2006 \\
\hline & $\begin{array}{c}\mathrm{B}[a] \mathrm{P}: \mathrm{B}[b] \mathrm{F} / \mathrm{DB}[a, h] \mathrm{A} / \mathrm{DB}[a, l] \mathrm{P} / 1-\mathrm{MP} \\
\mathrm{B}[a] \mathrm{P}: \mathrm{FLU}\end{array}$ & $\begin{array}{c}3: 3 / 1 / 0.1 / 30^{\mathrm{f}} \\
3: 30^{\mathrm{f}}\end{array}$ & & $1 \mathrm{~A} 1 / 2,2 \mathrm{~B} 6$ & No & $+(\exp )$ & $\begin{array}{l}+ \\
+\end{array}$ & Staal et al. 2007 \\
\hline & $\mathrm{B}[a] \mathrm{P}: \mathrm{B}[a] \mathrm{A} / \mathrm{B}[b] \mathrm{F} / \mathrm{B}[g h i] \mathrm{P} / \mathrm{CH} / \mathrm{CH} / \mathrm{DB}[a, h] \mathrm{A} / \mathrm{IP}$ & $1: 1^{\mathrm{f}}$ & & & & & + & Sevastyanova et al. 2007 \\
\hline & $\mathrm{B}[a] \mathrm{P}: \mathrm{B}[b] \mathrm{F} / \mathrm{DB}[a, h] \mathrm{A} / \mathrm{IP}$ & $1: 1^{\mathrm{r}^{-}}$ & & & & & + & \\
\hline & $\mathrm{B}[a] \mathrm{P}: \mathrm{B}[k] \mathrm{F}$ & $1: 1^{\mathrm{f}}$ & & & & & $\begin{array}{l}\mathrm{T} \\
-\end{array}$ & Tarantini et al. 2011 \\
\hline & $\mathrm{B}[a] \mathrm{P}: \mathrm{B}[a] \mathrm{A} / \mathrm{B}[g h i] \mathrm{P} / \mathrm{CHR} / \mathrm{FLU} / \mathrm{PYR}$ & $1: 1^{\mathrm{f}}$ & & & & & $=$ & \\
\hline & B $[a] \mathrm{P}: \mathrm{DB}[c, g] \mathrm{C}$ & $0.01-1: 1^{\mathrm{f}}$ & & 1A1 & No & $+(\exp )$ &,+- & Gabelova et al. 2013 \\
\hline \multirow{3}{*}{ Embryonic lung cells (human) } & $\mathrm{B}[a] \mathrm{P}: \mathrm{B}[a] \mathrm{A} / \mathrm{B}[b] \mathrm{F} / \mathrm{B}[k] \mathrm{F} / \mathrm{B}[g h i] \mathrm{P} / \mathrm{CHR} / \mathrm{DB}[a, h] \mathrm{A} / \mathrm{IP}$ & $1: 1^{-}$ & & & & & - & \\
\hline & $\mathrm{DB}[a, l] \mathrm{P}: \mathrm{B}[a] \mathrm{A} / \mathrm{B}[b] \mathrm{F} / \mathrm{B}[k] \mathrm{F} / \mathrm{B}[g h i] \mathrm{P} / \mathrm{CHR} / \mathrm{DB}[a, h] \mathrm{A} / \mathrm{IP}$ & $0.1: 0.1^{\mathrm{f}}$ & & & & & - & Binkova and Sram 2004 \\
\hline & $\mathrm{B}[a] \mathrm{P}: \mathrm{B}[a] \mathrm{A} / \mathrm{B}[b] \mathrm{F} / \mathrm{B}[\mathrm{k}] \mathrm{F} / \mathrm{B}[\mathrm{g} h i] \mathrm{P} / \mathrm{CHR} / \mathrm{DB}[a, h] \mathrm{A} / \mathrm{IP}$ & $1: 1^{1}$ & & & & & - & Sevastyanova et al. 2007 \\
\hline HT-29 cell (human) & FLU:B $[a] \mathrm{P}$ & $1-25: 1-25^{r}$ & & & No & + met) & & Harris et al.2013 \\
\hline \multirow{2}{*}{ Rat kidney cells } & $\mathrm{B}[a] \mathrm{P}: \mathrm{CHR}$ & $0.03-30: 3^{\mathrm{T}}$ & & $1 \mathrm{~A} 1,1 \mathrm{~B} 1$ & Yes & $-(\exp ),-(\mathrm{act})$ & & Falahatpisheh et al. 2004 \\
\hline & $\mathrm{B}[a] \mathrm{P}: \mathrm{ANT}$ & $0.03-30: 3^{\mathrm{f}}$ & & $1 \mathrm{~A} 1,1 \mathrm{~B} 1$ & Yes & $+(\exp ),-$ (act) & & \\
\hline WB-F344 cells (rat) & $\mathrm{B}[a] \mathrm{P}: \mathrm{DB}[c, g] \mathrm{C}$ & $0.01-1: 11^{\mathrm{f}}$ & & $1 \mathrm{~A} 1$ & No & $-(\exp )$ & - & Gabelova et al. 2013 \\
\hline \multirow{4}{*}{ Precision-cut rat liver slices } & $\mathrm{B}[a] \mathrm{P}: \mathrm{B}[b] \mathrm{F} / \mathrm{DB}[a, h] \mathrm{A} / \mathrm{DB}[a, l] \mathrm{P}$ & $3: 10 / 10 / 0.3^{\mathrm{r}}$ & & $1 \mathrm{~A} 2$ & No & $-(\exp )$ & - & \\
\hline & $\mathrm{B}[a] \mathrm{P}: \mathrm{FLU}$ & $3: 30^{\mathrm{f}}$ & & $1 \mathrm{~A} 2$ & No & $+(\exp )$ & + & \\
\hline & $\mathrm{DB}[a, h] \mathrm{A}: \mathrm{DB}[a, l] \mathrm{P} / \mathrm{FLU}$ & $10: 0.3 / 30^{\mathrm{f}}$ & & $1 \mathrm{~A} 2$ & No & $-(\exp )$ & - & Staal et al. 2008 \\
\hline & All mixtures & & & $1 \mathrm{~A} 1$ & No & $+(\exp )$ & & \\
\hline Hamster embryo cells & $\mathrm{B}[e] \mathrm{P}: \mathrm{B}[a] \mathrm{P}$ & $0-5^{a}: 11.2-18.9^{b^{6}}$ & & & & & + & Smolarek and Baird 1984 \\
\hline
\end{tabular}

Abbreviations: 1-MP, 1-methylphenanthrene; 1-NP, 1-nitropyrene; act, EROD activity; ANT, anthracene; $\mathrm{B}[a] \mathrm{A}$, benz $[a]$ anthracene; $\mathrm{B}[a] \mathrm{P}$, benzo $[a]$ pyrene; $\mathrm{B}[b] \mathrm{F}, \mathrm{benzo}[b] \mathrm{fluoranthene;} \mathrm{B}[e] \mathrm{P}$, benzo $[e] \mathrm{pyrene} ; \mathrm{B}[$ ghi $] \mathrm{P}$, benzo $[g h i]$ perylene; $\mathrm{B}[k] \mathrm{f}$, benzo[k]fluoranthene; CHR, chrysene; $\mathrm{DB}[a, e] \mathrm{P}$, dibenzo $[a, e]$ pyrene; $\mathrm{DB}[a, h] \mathrm{A}$, dibenz $[a, h]$ anthracene; $\mathrm{DB}[a, l] \mathrm{P}$, dibenzo $[a, l]$ pyrene; $\mathrm{DB}[c, g] \mathrm{C}, \operatorname{dibenzo}[c, g]$ carbazole; $\mathrm{DMBA}, 7,12-$ dimethylbenz $[a]$ anthracene; exp, gene expression; FLU, fluoranthene; i.p., intraperitoneal; i.v., intravenous; IP, indeno[123-cd]pyrene; met, metabolism; NAP, naphthalene; PYR, pyrene

Symbol guide: ${ }^{\mathrm{a}}, \mathrm{nmol} ;{ }^{\mathrm{b}}, \mu \mathrm{g} ;{ }^{\mathrm{c}}, \mu \mathrm{mol} / \mathrm{kg} ;{ }^{\mathrm{d}}, \mathrm{mg} / \mathrm{kg} ;{ }^{\mathrm{e}}, \mu \mathrm{g} / \mathrm{L} ;{ }^{\mathrm{f}}, \mu \mathrm{M} ;+$, increase compared to PAH alone; -, decrease compared to PAH alone; =, no observed difference in effect compared to PAH alone; 
Table 2: Summary of the effects on CYP450s and DNA adduct formation after in vivo and in vitro co-exposure to complex PAH mixtures compared to individual PAH effects

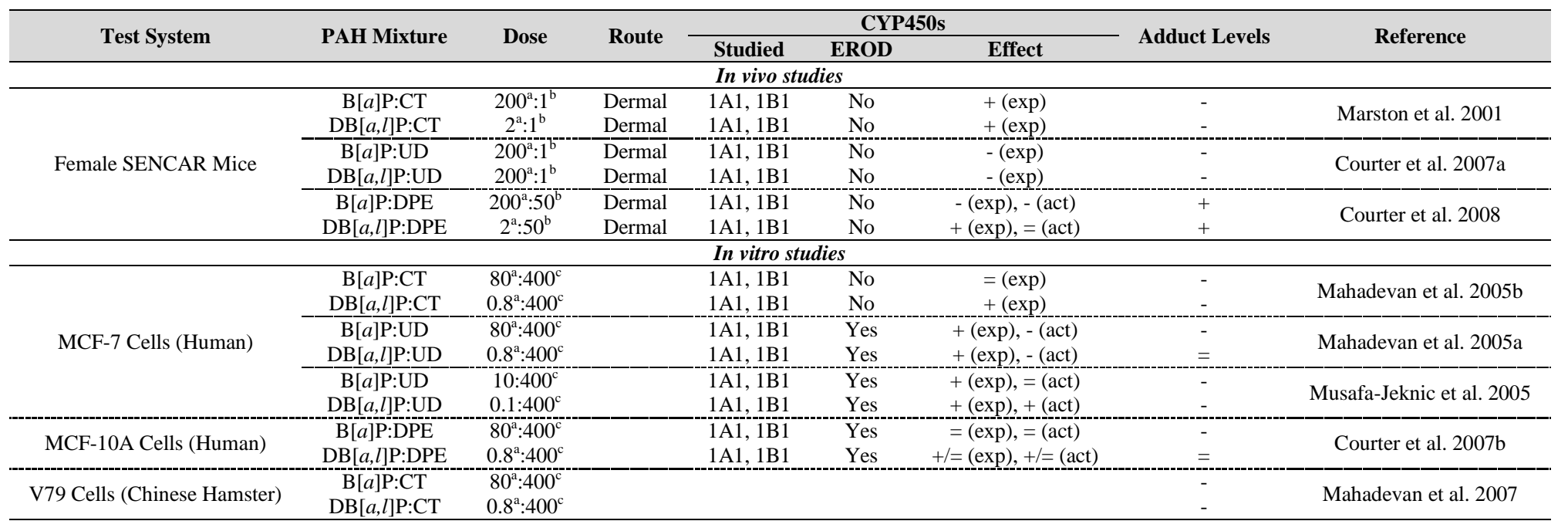

Abbreviations: B $[a] \mathrm{P}$, benzo $[a]$ pyrene; CSC, cigarette smoke condensate; CT, coal tar; DB $[a, l] \mathrm{P}$, dibenzo $[a, l]$ pyrene; DPE, diesel particulate extract; DPM, diesel particulate matter; UD, urban dust

Symbol guide: ${ }^{\mathrm{a}}, \mathrm{nmol} ;{ }^{\mathrm{b}}, \mathrm{mg} ;{ }^{\mathrm{c}}, \mu \mathrm{g} ;{ }^{\mathrm{d}}, \mathrm{mgSRMeq} / \mathrm{mlCrudeExtract} ;+$, increase compared to PAH alone; -, decrease compared to PAH alone; =, no observed difference in effect compared to PAH alone 
Bay region<smiles>Cc1ccc2cccc3ccc4cc5ccccc5c(c1)c4c23</smiles>

Benzo[a]pyrene

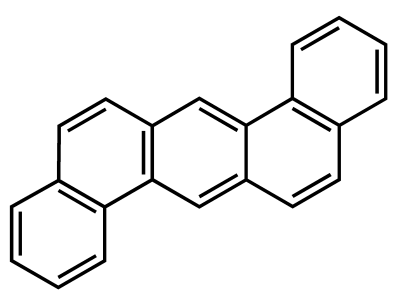

Dibenz $[a, h]$ anthracene
Fjord region<smiles></smiles>

Dibenzo $[a, l]$ pyrene

\section{Sterically-hindered}

bay region<smiles>Cc1c2ccccc2c(C)c2c1ccc1ccccc12</smiles>

dimethylbenz $[a]$ anthracene<smiles>O=C1c2ccccc2C(=O)c2c1ccc1ccccc21</smiles>

benz $[a]$ anthracene-7,12-dione<smiles>O=[N+]([O-])c1ccc2ccc3cccc4ccc1c2c34</smiles>

1-nitropyrene 


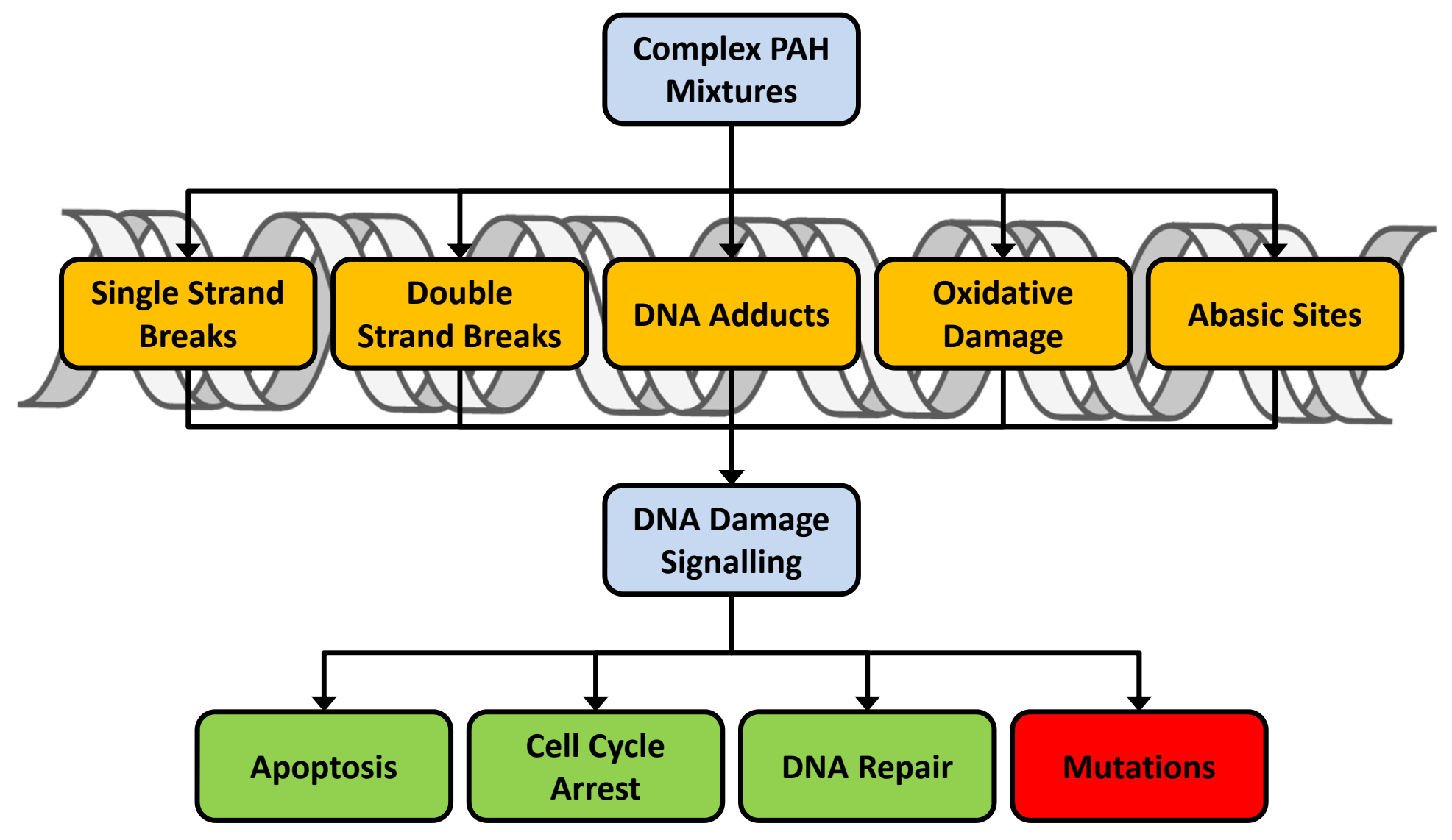

